\title{
Critical appraisal of paclitaxel balloon angioplasty for femoral-popliteal arterial disease
}

This article was published in the following Dove Press journal:

Vascular Health and Risk Management

29 August 2016

Number of times this article has been viewed

\author{
Monika Herten' \\ Giovanni B Torsello ${ }^{1,2}$ \\ Eva Schönefeld ${ }^{3}$ \\ Stefan Stahlhoff ${ }^{2}$ \\ 'Department of Vascular and \\ Endovascular Surgery, University \\ Hospital Münster, ${ }^{2}$ Department of \\ Vascular Surgery, St Franziskus \\ Hospital, Münster, ${ }^{3}$ Institute for \\ Education and Student Affairs, \\ University Hospital Münster, Münster, \\ Germany
}

\begin{abstract}
Peripheral arterial disease, particularly critical limb ischemia, is an area with urgent need for optimized therapies because, to date, vascular interventions often have limited life spans. In spite of initial encouraging technical success after femoropopliteal percutaneous transluminal angioplasty or stenting, postprocedural restenosis remains the major problem. The challenging idea behind the drug-coated balloon (DCB) concept is the biological modification of the injury response after balloon dilatation. Antiproliferative drugs administered via DCBs or drug-eluting stents are able to suppress neointimal hyperplasia, the main cause of restenosis. This article reviews the results of DCB treatments of femoropopliteal and infrapopliteal lesions in comparison to standard angioplasty with uncoated balloons. A systematic literature search was performed in 1) medical journals (ie, MEDLINE), 2) international registers for clinical studies (ie, www.clinicaltrials.gov), and 3) abstracts of scientific sessions. Several controlled randomized trials with follow-up periods of up to 5 years demonstrated the efficacy of paclitaxel -DCB technology. However, calcified lesions seem to affect the efficacy of DCB. Combinations of preconditioning methods with DCBs showed promising results. Although the mechanical abrasion of calcium via atherectomy or laser ablation showed favorable periprocedural results, the long-term impact on restenosis and clinical outcome has to be demonstrated. Major advantages of the DCBs are the rapid delivery of drug at uniform concentrations with a single dose, their efficacy in areas wherein stents have been contraindicated until now (ie, bifurcation, ostial lesions), and in leaving no stent scaffold behind. Reinterventions are easier to perform because DCBs leave no metal behind. Various combinations of DCBs with other treatment modalities may prove to be viable options in future. The follow-up results of clinical studies will evaluate the long-term impact of DCBs.
\end{abstract}

Keywords: drug-coated balloon, critical limb ischemia, peripheral artery disease, restenosis, atherectomy, stent restenosis

\section{Limitations of prevailing angioplasty/stenting treatments in superficial femoral artery}

Endovascular treatment of femoropopliteal lesions is complicated by the fact that the superficial femoral artery (SFA) is one of the longest vessels in the body, reaching up to $30 \mathrm{~cm}$ in length. The artery is most dynamically active with regard to hip and knee motion, undergoing torsion, compression, flexion, and extension. It is also prone to atherosclerosis because of low shear stress and spiral blood flow.

The treatment of femoropopliteal stenosis by percutaneous transluminal angioplasty (PTA) results in restenosis rates of up to $58 \%$ in the first 6-12 months. ${ }^{1,2}$
Department of Vascular and Endovascular Surgery, University Hospital Münster, Albert-Schweitzer-Campus I, Building W30, $48 \mid 49$ Münster, Germany Tel $+4925 I 835 \quad 1717$

$\mathrm{Fax}+492518346502$

Email Moherten@web.de 
During balloon inflation, an injury in the vascular wall is likely to be created, which can trigger subsequent biological processes. These comprise immediate elastic recoil of the arterial wall, intimal dissection, and negative vascular remodeling by neointimal hyperplasia. Stenting can prevent the elastic recoil and dissection and, thereafter, the risk of early occlusion. But stenting alone is not able to inhibit neointimal proliferation; it can even be stimulated by the stent struts. The process underlying neointimal proliferation is the activation of the smooth muscle cells (SMCs) in the media and their production of excessive extracellular matrix material, generating the restenosis. This overshooting biological response to vascular injury leads to loss of primary patency (PP), late lumen loss (LLL), occlusion, and/or the need for target lesion revascularization (TLR). ${ }^{3}$

\section{Biological modification of the injury response by drug-coated balloons}

Biological modification of the injury response can be achieved by suppressing SMC activation, the main cause for neointimal hyperplasia. Drug-coated balloons (DCBs) and drug-coated stents (DCS) allow for local application of cytostatic substances. Up to now, the antiproliferative taxane paclitaxel (PTX) has been the most commonly used drug for DCB technology. Because of its lipophilic chemistry, it can be passively absorbed through the cell membrane and is retained within the vessel wall, where it can display its sustained effect. ${ }^{4,5}$ By inhibiting the disassembly of microtubules, it stops cell division and inhibits cell differentiation and cell migration. ${ }^{6}$

PTX selectively inhibits SMC activation and the succeeding synthesis of excessive extracellular matrix material: while high PTX concentrations display a cytotoxic effect on all cell types, Axel et al showed that human arterial SMCs were more sensitive toward PTX than human arterial endothelial cells. Low concentrations of PTX inhibited cell proliferation to a greater extent in SMCs than in endothelial cells and resulted in prevention of restenosis without stopping reendothelialization. ${ }^{6}$

Preclinical studies already revealed that a single application of PTX can lead to complete inhibition of SMC proliferation and cell migration for $>2$ weeks. The effect is independent of the duration of application: there was no difference between a 24-hour continuous administration and a single-bolus administration for 20 minutes. ${ }^{6}$ Drug transfer via adherence to the vessel wall is eased by carrier excipients. ${ }^{7}$ Inflation using a single balloon with a contact time of
$<1$ minute was adequate to provide uniform deliverability of sufficient PTX into the vessel wall. ${ }^{8}$

In animal arteries, neointima formation was inhibited maximally by using a PTX dosage up to $3 \mu \mathrm{g} / \mathrm{mm}^{2}{ }^{4}$ From this PTX, which is $\sim 9 \mathrm{mg}$ for a DCB of $\varnothing 8 \mathrm{~mm}$ and $120 \mathrm{~mm}$ length, $\sim 25 \%-35 \%$ permeated into the vessel wall, $10 \%$ persisted on the balloon catheter after insertion, and up to $60 \%$ was lost into the blood stream. ${ }^{7}$ In a first-in-human safety and dose-finding study about systemic nanoparticle albumin-bound paclitaxel (nab-PTX) for in-stent restenosis (ISR)(SNAPIST-I trial), no significant adverse events were attributable to nab-PTX at $10 \mathrm{mg} / \mathrm{m}^{2}$ or $30 \mathrm{mg} / \mathrm{m}^{2}$. Moderate neutropenia, moderate sensory neuropathy, and mild-tomoderate reversible alopecia occurred only at doses of $70 \mathrm{mg} /$ $\mathrm{m}^{2}$ and $100 \mathrm{mg} / \mathrm{m}^{2}$ body surface area. ${ }^{9}$ In tumor therapy, the recommended PTX dosage is $\sim 175 \mathrm{mg} / \mathrm{m}^{2}$.

For peripheral application, all actual DCBs and the drugeluting stents (DESs) currently approved in Europe and the US use PTX as cytostatic substance. In preclinical studies, other cytostatic agents are currently being investigated for use in DCBs for the peripheral region. For DESs of the coronary system, apart from PTX, other drugs such as sirolimus, everolimus, and zotarolimus are also currently used.

\section{Are all DCBs equal? Features of current PTX-DCBs}

Till date, there are about a dozen DCBs containing PTX concentrations of 2-3.5 $\mu \mathrm{g}$ PTX $/ \mathrm{mm}^{2}$ available in Europe (CE marked). Two of them have received US Food and Drug Administration (FDA) approval in the US after providing Level I scientific evidence.

The DCBs differ in the excipients added (iopromide, urea, shellac, polysorbate-and-sorbitol, butyryl trihexyl citrate, citric acid ester, dextran, polyethylene glycol, or none) and also in the product-specific coating technology used. The PTX homogeneity varies among the following forms: crystalline aggregates, hybrid crystalline, or amorphous. In order to avoid any downstream embolization potentially caused by PTX, it is desirable to lose no PTX during handling, insertion, and delivery of the device.

Therefore, new technologies aim for minimization of drug loss and concurrent optimization of both deliverability and absorption of the drug in the vessel wall.

The complexities of the DCBs are defined by their mechanical and pharmacological elements: ${ }^{10}$ The construction type of the balloon and its material properties have significant effects upon how PTX and the excipient interact with the balloon and how well they are transferred into the 
vessel wall. Moreover, the excipient characteristics and the mixture of PTX and excipient can be important for the drug retention at the wall. Finally, the coating and the unfolding principle of the balloon are significant. All these aspects almost certainly make a difference in terms of performance and clinical characteristics of the available DCBs. ${ }^{10}$

Summing up all these aspects, different DCBs are not similar or comparable, and their efficacy in terms of inhibition of neointimal proliferation is different as demonstrated in animal studies ${ }^{7,11}$ and in an observational study of 1,129 patients. ${ }^{12}$ The efficacy and safety of most DCBs available in Europe are supported by clinical data from prospective randomized trials. ${ }^{13}$ But long-term follow-up (FU) data (of $>3$ years) are needed to provide evidence of their superiority over other treatment methods. Comparing every DCB against all others is hardly possible because it would require thousands of patients for a sufficiently powerful study. ${ }^{13}$

\section{Outcomes of randomized controlled trials with DCBs in SFA and registry reports}

First randomized controlled trials (RCTs) comparing PTXDCBs vs standard uncoated PTA (=control) in the SFA are listed in Table 1. Most studies evaluated small groups with $<100$ patients. Regarding the patients' characteristics, the proportion of diabetic patients was up to $55 \%$, with up to $8 \%$ comprising critical limb ischemia (CLI) patients. ${ }^{14-17}$ Lesion characteristics included a mean lesion length of $57-80 \mathrm{~mm}$; more than half of the lesions were de novo lesions $(63 \%-95 \%)$, $50 \%-66 \%$ were calcified lesions, and $13 \%-42 \%$ were total occlusions. Bailout stenting rates were $<10 \%$ in the majority of DCB groups (except the Paclitaxel-coated balloons In Femoral Indication to dEfeat Restenosis trial - PACIFIER, ${ }^{16}$ with 21\%) and significantly higher in the control (PTA-only) groups. After 6 months and 12 months, the clinical parameters (Rutherford classification $[\mathrm{RU}]$ and ankle-brachial index $[\mathrm{ABI}])$ improved significantly $(P \leq 0.05)$ in most trials compared to the preinterventional values. In the femoral paclitaxel (FemPac) trial, ${ }^{15}$ the improvement of RU was significantly higher in the DCB group than in the uncoated control at 6 months (Table 1).

All studies listed in Table 1 showed the superiority of PTX-DCB angioplasty vs uncoated control PTA in TransAtlantic InterSociety Consensus (TASC) IIA and IIB femoropopliteal lesions. In terms of the primary end points, LLL after 6 months and TLR at 12 months (Figure 1A and B) were superior in the DCB groups.

The predominance of DCB therapy over PTA alone in these cited RCTs (THUNDER, ${ }^{14}$ FemPac,${ }^{15}$ PACIFIER, ${ }^{16}$ LEVANT $\mathrm{I}^{17}$ ) was also confirmed in a meta-analysis: PTXDCB therapy was associated with superior antirestenotic

Table I Early clinical trials of DCB vs PTA in femoropopliteal lesions

\begin{tabular}{|c|c|c|c|c|c|c|c|c|}
\hline \multirow{3}{*}{$\begin{array}{l}\text { Femoropopliteal RCT } \\
\text { DCB type used }\end{array}$} & \multicolumn{2}{|c|}{ THUNDER ${ }^{14}$} & \multicolumn{2}{|c|}{ FemPac $^{15}$} & \multicolumn{2}{|c|}{ PACIFIER $^{16}$} & \multicolumn{2}{|c|}{ LEVANT I ${ }^{17}$} \\
\hline & \multicolumn{2}{|c|}{ 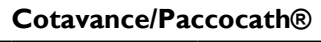 } & \multicolumn{2}{|c|}{ Cotavance/Paccocath® } & \multicolumn{2}{|c|}{ IN.PACT TM Pacific } & \multicolumn{2}{|c|}{ Moxy/Lutonix® } \\
\hline & DCB & PTA & DCB & PTA & DCB & PTA & DCB & PTA \\
\hline \multicolumn{9}{|l|}{ Characteristics } \\
\hline Number of patients (n) & 48 & 54 & 45 & 42 & 41 & 44 & 49 & 52 \\
\hline Diabetics (\%) & 50 & 46 & 40 & 55 & 43 & 28 & 45 & 50 \\
\hline CLI (\%) & & & 4 & 7 & 4 & 0 & 6 & 8 \\
\hline Lesion length $(\mathrm{mm})^{\mathrm{a}}$ & $75 \pm 62$ & $74 \pm 65$ & 57 & 61 & $7 \pm 53$ & $66 \pm 55$ & $81 \pm 37$ & $80 \pm 38$ \\
\hline De novo lesion (\%) & 63 & 83 & 64 & 67 & 68 & 83 & 90 & 88 \\
\hline Total occlusion (\%) & 27 & 26 & 13 & 19 & 23 & 38 & $4 I$ & 42 \\
\hline Calcified lesion (\%) & 50 & 52 & 53 & 52 & 64 & 66 & & \\
\hline Bailout stenting (\%) & 4 & 22 & 9 & 14 & 21 & 34 & 2.7 & 15.8 \\
\hline \multicolumn{9}{|l|}{6 months } \\
\hline Improvement RU & $\sqrt{ }$ & $\sqrt{ }$ & Yes & $\sqrt{ }$ & $\sqrt{ }$ & $\sqrt{ }$ & $\sqrt{ }$ & $\sqrt{ }$ \\
\hline Improvement $\mathrm{ABI}$ & $\sqrt{ }$ & $\sqrt{ }$ & & & & & & \\
\hline \multicolumn{9}{|l|}{12 months } \\
\hline Improvement RU & & & $\sqrt{ }$ & $\sqrt{ }$ & & & $\sqrt{ }$ & $\sqrt{ }$ \\
\hline Improvement $A B \mid$ & & & & & & & $\sqrt{ }$ & $\sqrt{ }$ \\
\hline
\end{tabular}

Notes: $\sqrt{ }$ Indicates significant improvement. ${ }^{\text {aD }}$ ata presented as mean \pm standard deviation. Cotavance/Paccocath® DCB (Medrad, Bayer Healthcare, Berlin, Germany); Moxy/Lutonix ${ }^{\circledR}$ DCB (BARD Peripheral Vascular, Inc, Tempe, AZ, USA); IN.PACT TM Pacific DCB (Medtronic GmbH, Meerbusch, Germany); FemPac, Femoral Paclitaxel Randomized Pilot Trial - Inhibition of Restenosis in Femoropopliteal Arteries: Paclitaxel-Coated vs Uncoated Balloon; LEVANT I, Trial Comparing the Lutonix Catheter vs Standard Balloon Angioplasty for Treatment of Femoropopliteal Arteries With and Without Stenting; PACIFIER, Paclitaxel-coated balloons In Femoral Indication to dEfeat Restenosis trial; THUNDER, Local Delivery of Paclitaxel to Inhibit Restenosis during Angioplasty of the Leg Trial. Adapted with permission from Herten M, Schönefeld E, Stahlhoff S, Schwindt A, Torsello GB. Drug-coated balloons in the treatment of femoro- and infra-popliteal lesions. Interv Cardiol. 2015;7(4):353-370.72

Abbreviations: ABI, ankle-brachial index; CLI, critical limb ischemia; DCB, drug-coated balloon; PTA, percutaneous transluminal angioplasty; RCT, randomized controlled trial; RU, Rutherford classification. 
A

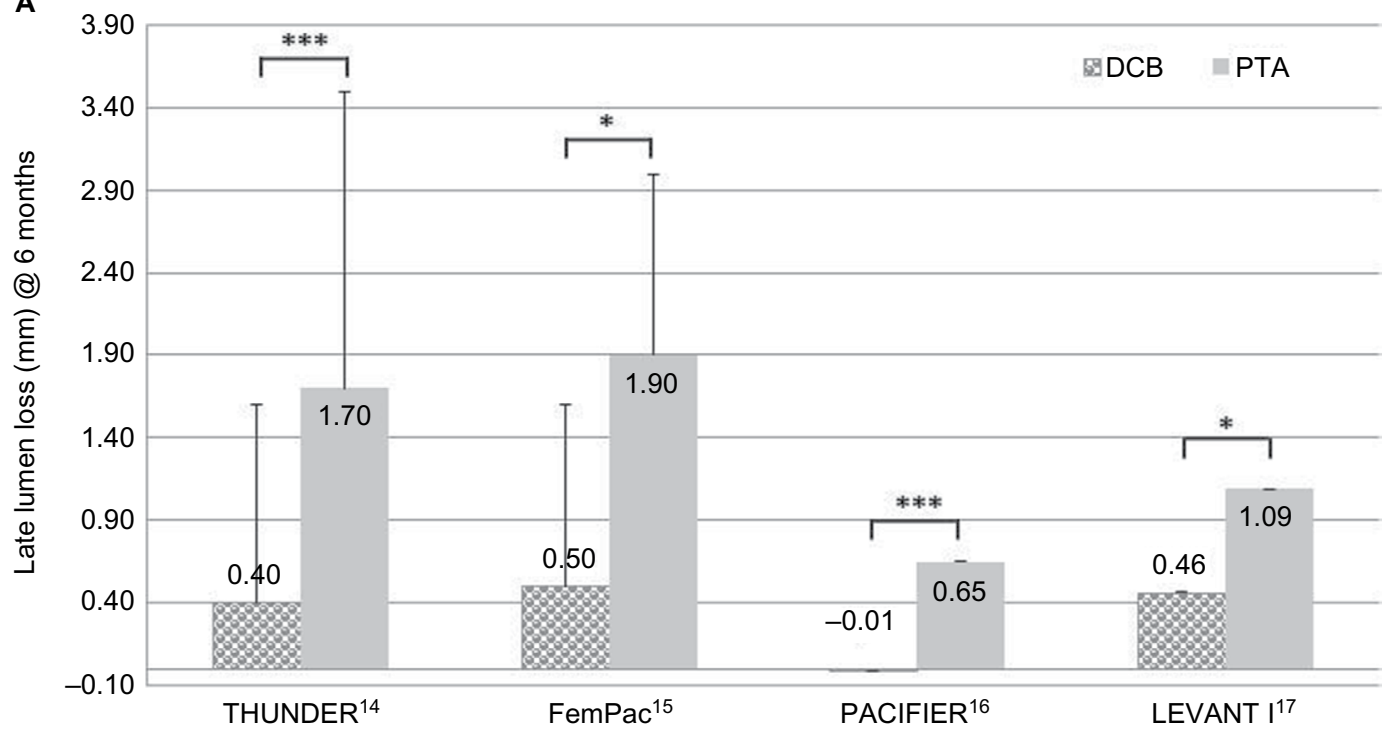

B

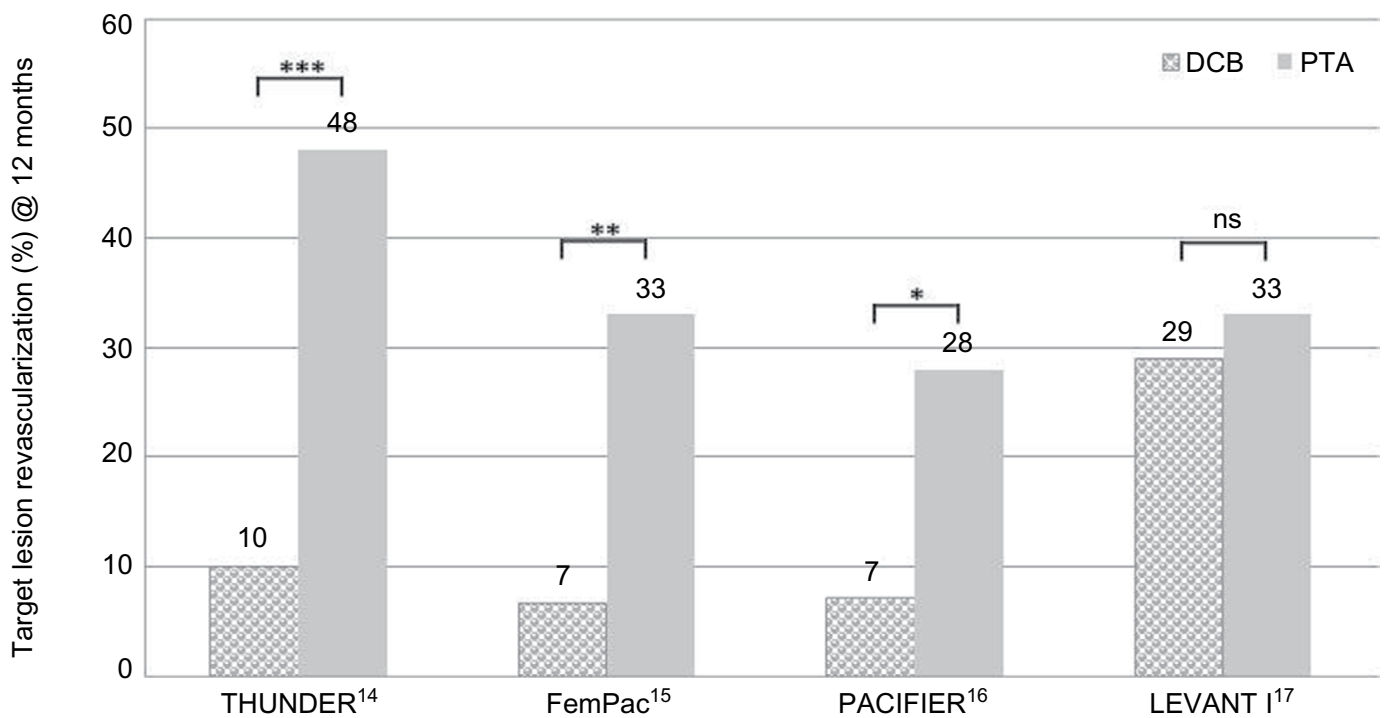

Figure I Early clinical trials of DCB vs PTA in femoropoliteal lesions.

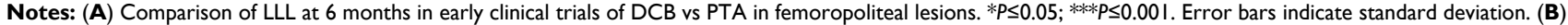
Comparison of TLR at 12 months in early clinical trials of DCB vs PTA in femoropoliteal lesions. *P $\leq 0.05$; **P $\leq 0.01$; ***P $\leq 0.00$ I. THUNDER, Local Delivery of Paclitaxel to Inhibit Restenosis during Angioplasty of the Leg Trial; FemPac, Femoral Paclitaxel Randomized Pilot Trial - Inhibition of Restenosis in Femoropopliteal Arteries: PaclitaxelCoated vs Uncoated Balloon; PACIFIER, Paclitaxel-coated balloons In Femoral Indication to dEfeat Restenosis trial; LEVANT I, Trial Comparing the Lutonix Catheter vs Standard Balloon Angioplasty for Treatment of Femoropopliteal Arteries With and Without Stenting.

Abbreviations: DCB, drug-coated balloon; LLL, late lumen loss; ns, not significant; PTA, percutaneous transluminal angioplasty; TLR, target lesion revascularization.

efficacy at 12 months without any evidence of a variance in safety profile. ${ }^{18}$

In the early trials, the difference between bailout stenting rates and the reintervention in the DCB groups vs the control groups was much greater, giving rise to a debate about bias: in most of the studies, the interventionalists performing the actual standard procedure were not blinded and were responsible for the TLR decision.
However, as a consequence, in recently published RCTs, LEVANT $\mathrm{II}^{19}$ and IN.PACT SFA II, ${ }^{20}$ the trial design tried to exclude this limitation to avoid a bias: investigators carrying out the actual procedure did not participate in clinical decision making at the end of the intervention. In both studies, the TLR decision was performed by a blinded, independent clinical event committee that adjudicated all major adverse events, while independent core laboratories analyzed all 
images, including duplex ultrasonography and angiography images, creating a situation that was close to double blinded.

Both actual trials IN.PACT SFA and LEVANT II comprise much larger group sizes: IN.PACT SFA, including the IN.PACT SFA I trial (conducted in Europe) and the IN.PACT SFA II trial (conducted in the US), included 220 patients assigned to the DCB group vs 110 patients in the control group. The LEVANT II trial investigated the outcome in 316 patients of the DCB group compared to 160 patients treated with the uncoated balloon (Table 2). The study population comprised $\sim 50 \%$ diabetic patients and $\leq 8 \%$ CLI patients. Lesion characteristics contained a mean lesion length of 63-88 mm, with high impact of de novo lesions (95\%) in the IN.PACT SFA trial. In the LEVANT II trial, 57\%-59\% of the lesions were calcified and $21 \%-26 \%$ were totally occluded. Bailout stenting rates were $3 \%-8 \%$ within the DCB group and slightly higher in the control (PTA-only) group (7\%-13\%). Outcome at 12 months revealed significantly improved $(\sqrt{ })$ RU compared to the preinterventional values in both trials. Outcomes of the clinical parameters were superior with DCBs for ABI in the IN.PACT SFA trial and for RU in the LEVANT II trial (Table 2). In both studies, TLR was lower in the DCB group compared to the control but without significance (Figure 2).

In all trials and registries mentioned herein, predilation with standard PTA balloon was performed before DCB use. The effect of predilation vs direct use of DCBs on DCB outcome was investigated in a subgroup analysis (58 vs 37 lesions) of the ILLUMENATE FIH study. ${ }^{21}$ The predilation cohort contained more severe calcified lesions and more total occlusions ( $13.8 \%$ vs $2.7 \%$ and $12.1 \%$ vs $5.4 \%$, respectively). Although at 6 months, LLL was less for the direct cohort $(0.08 \%$ vs $0.54 \mathrm{~mm})$, indicating a good drug effect, at 12 months, PP was superior in the predilation cohort (89.5\% vs $77.5 \%$ ). The number of amputations necessary was one in the direct and none in the predilation cohort. The authors concluded that direct use of the DCB without predilation may be optional in simple lesions..$^{21}$ The 2 -year results presented a PP rate of $80.3 \%$. The freedom from clinically driven TLR, per Kaplan-Meier estimate, decreased slightly from $90.0 \%$ at 12 months to $85.8 \%$ at 24 months. ${ }^{22}$

Summarizing the use of DCBs in the SFA, DCB treatment was superior to the control at 12 months. Regarding the long-term data, 24 months' data were already available for most of the studies and for up to 60 months in the THUNDER study. ${ }^{14}$ Figure 3 illustrates the freedom from TLR over time. For all DCB groups (reddish colored symbols), freedom from TLR was much higher than that for the control groups (blue-colored symbols) at 6 months, 12 months, and 24 months. In both treatment groups, there was a decrease over time. There seems to be no influence of lesion length on DCB efficacy. Even after 60 months, the DCB group of the THUNDER study reached a rate of freedom from TLR value that was as high as the 12-month results of the control groups

Table 2 Recent clinical trials of DCB vs PTA and registries of DCB use in the SFA

\begin{tabular}{|c|c|c|c|c|c|}
\hline \multirow{3}{*}{$\begin{array}{l}\text { Femoropopliteal RCT } \\
\text { DCB type used }\end{array}$} & \multicolumn{2}{|c|}{ IN.PACT SFA ${ }^{20}$} & \multicolumn{2}{|c|}{ LEVANT I/ ${ }^{19}$} & \multirow{3}{*}{$\begin{array}{l}\text { ILLUMENATE FIH }^{2 I} \\
\text { Stellarex }^{\text {TM }} \\
\text { DCB }\end{array}$} \\
\hline & \multicolumn{2}{|c|}{ IN.PACT ${ }^{\mathrm{TM}}$ Admiral } & \multicolumn{2}{|c|}{ Lutonix@ } & \\
\hline & DCB & PTA & DCB & PTA & \\
\hline \multicolumn{6}{|l|}{ Characteristics } \\
\hline Number of patients (n) & 220 & $\mathrm{III}$ & 316 & 160 & $50 / 58$ \\
\hline Diabetics (\%) & 41 & 49 & 43 & 43 & 34 \\
\hline CLI (\%) & 5 & 5 & 8 & 8 & 2 \\
\hline Lesion length $(\mathrm{mm})^{\mathrm{a}}$ & $89 \pm 49$ & $88 \pm 51$ & $63 \pm 41$ & $63 \pm 40$ & $72 \pm 47$ \\
\hline De novo lesion (\%) & 95 & 95 & & & 100 \\
\hline Total occlusion (\%) & 26 & 20 & 21 & 22 & 12 \\
\hline Calcified lesion (\%) & & & 59 & 57 & 62 \\
\hline Severe calcification (\%) & 8 & 6 & & & \\
\hline Bailout stenting (\%) & 8 & 13 & 3 & 7 & 8 \\
\hline \multicolumn{6}{|l|}{ I 2 months } \\
\hline Improvement RU & $\sqrt{ }$ & $\sqrt{ }$ & Yes & $\sqrt{ }$ & \\
\hline Improvement $\mathrm{ABI}$ & Yes & $\sqrt{ }$ & & & \\
\hline
\end{tabular}

Notes: $\sqrt{ }$ Indicates significant improvement. ${ }^{2}$ Data presented as mean \pm standard deviation. IN.PACT TM Admiral DCB (Medtronic GmbH, Meerbusch, Germany); Lutonix $\AA$ DCB (BARD Peripheral Vascular, Inc, Tempe, AZ, USA); Stellarex DCB TM (Spectranectrics, Colorado Springs, CO, USA); IN.PACT SFA, Randomized Trial of IN.PACT Admiral ${ }^{\mathrm{TM}}$ Drug Eluting Balloon vs Standard PTA for the Treatment of Superficial Femoral and/or Popliteal Peripheral Artery Disease; LEVANT II, The Lutonix PaclitaxelCoated Balloon for the Prevention of Femoropoliteal Restenosis; ILLUMENATE FIH, Study to Evaluate Treatment of Obstructive Superficial Femoral Artery or Popliteal Lesions With A Novel Paclitaxel-Coated Percutaneous Angioplasty Balloon. Adapted with permission from Herten M, Schönefeld E, Stahlhoff S, Schwindt A, Torsello GB. Drug-coated balloons in the treatment of femoro- and infra-popliteal lesions. Interv Cardiol. 20I5;7(4):353-370. ${ }^{72}$

Abbreviations: $\mathrm{ABI}$, ankle-brachial index; CLI, critical limb ischemia; DCB, drug-coated balloon; LLL, late lumen loss; PTA, percutaneous transluminal angioplasty; RCT, randomized controlled trial; RU, Rutherford classification; SFA, superficial femoral artery. 


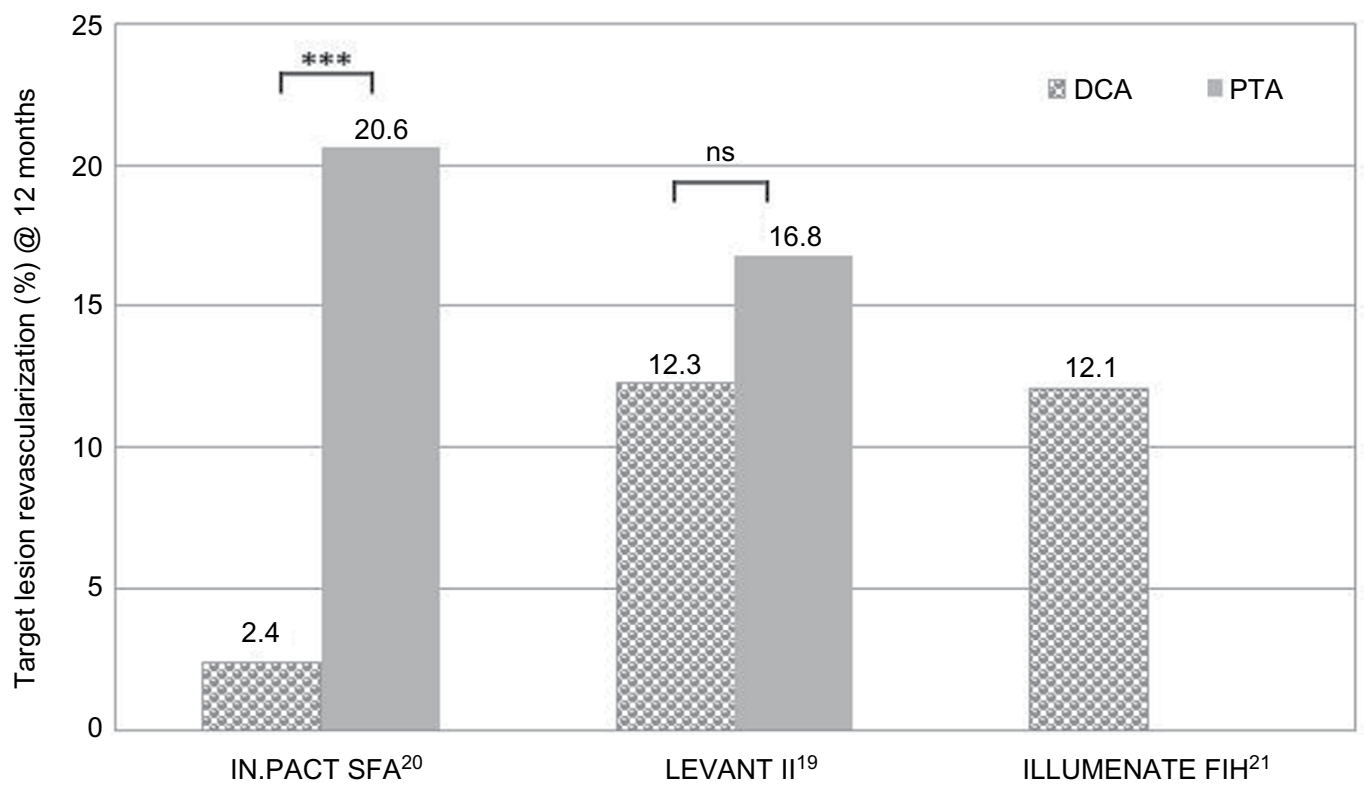

Figure 2 Comparison of TLR at 12 months in recent clinical trials of DCB vs PTA in femoropopliteal lesions.

Notes: ***P $\leq 0.001$. IN.PACT SFA, Randomized Trial of IN.PACT Admiral TM Drug Eluting Balloon vs Standard PTA for the Treatment of Superficial Femoral and/or Popliteal Peripheral Artery Disease; LEVANT II, The Lutonix Paclitaxel-Coated Balloon for the Prevention of Femoropoliteal Restenosis; ILLUMENATE FIH, Study to Evaluate Treatment of Obstructive Superficial Femoral Artery or Popliteal Lesions With A Novel Paclitaxel-Coated Percutaneous Angioplasty Balloon.

Abbreviations: DCB, drug-coated balloon; ns, not significant; PTA, percutaneous transluminal angioplasty; TLR, target lesion revascularization.

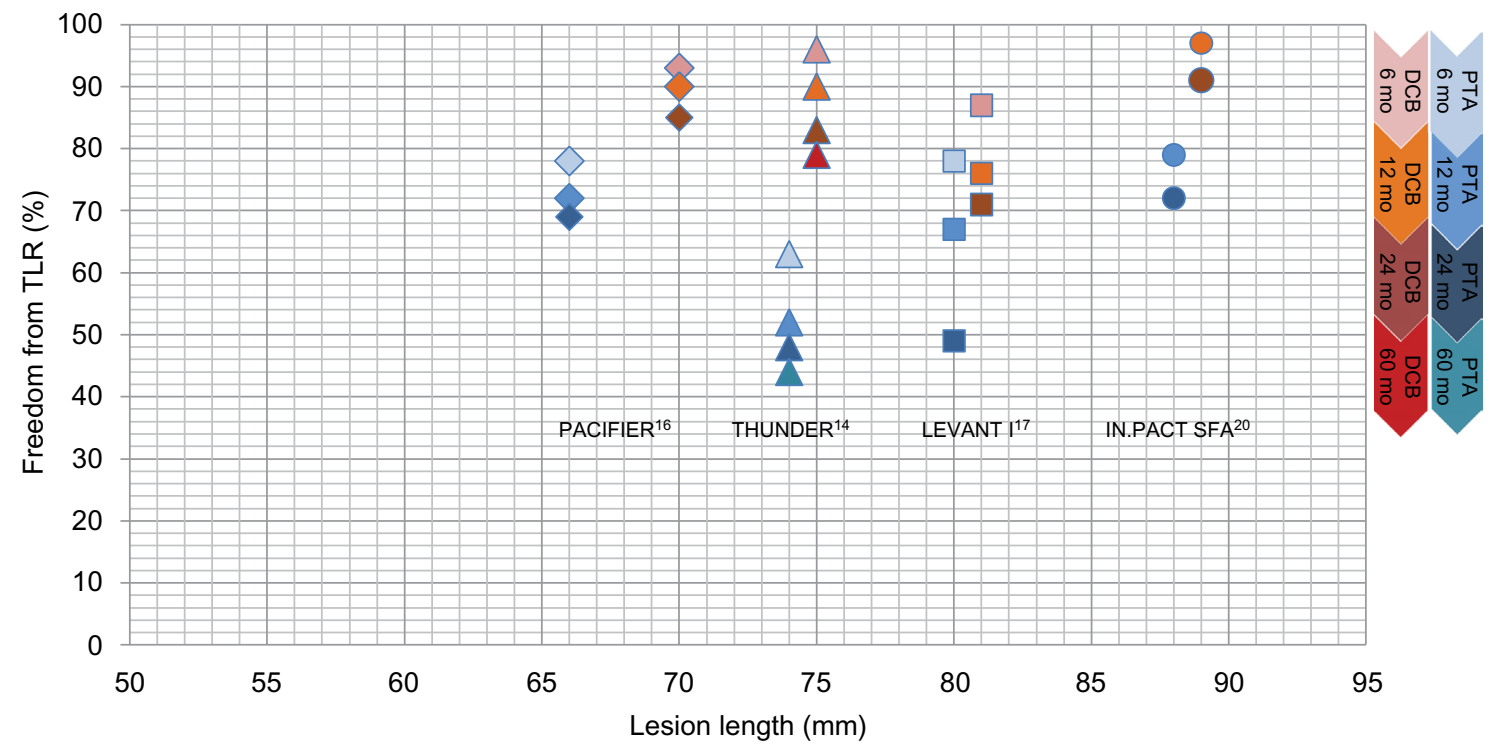

Figure 3 Development of freedom from TLR over time in clinical trials of DCB vs PTA in the SFA.

Notes: PACIFIER, Paclitaxel-coated balloons In Femoral Indication to dEfeat Restenosis trial; THUNDER, Local Delivery of Paclitaxel to Inhibit Restenosis during Angioplasty of the Leg Trial; LEVANT I, Trial Comparing the Lutonix Catheter vs Standard Balloon Angioplasty for Treatment of Femoropopliteal Arteries With and Without Stenting; IN.PACT SFA, Randomized Trial of IN.PACT Admiral ${ }^{\text {TM }}$ Drug Eluting Balloon vs Standard PTA for the Treatment of Superficial Femoral and/or Popliteal Peripheral Artery Disease.

Abbreviations: DCB, drug-coated balloon; PTA, percutaneous transluminal angioplasty; SFA, superficial femoral artery; TLR, target lesion revascularization; mo, months. 
of the LEVANT I and IN.PACT SFA trials. Although in the THUNDER analysis of end points at 5-year FU, the sample size was small ( $n=22$ vs 25 ), there were significantly lower values of LLL and TLR, as well as a longer time span until reintervention in the DCB group compared to the control even after 5 years. ${ }^{23}$ No signs of drug-related local vessel abnormality could be detected. ${ }^{24}$

\section{Outcomes of DCB use in below- the-knee lesions: RCTs and complications}

RCTs and registries in the peripheral arteries for the region below the knee (BTK) are listed in Table 3. In most of the studies, $>50 \%$ or up to $100 \%$ of the patients were diabetics. Apart from the DEBELLUM study ${ }^{25}$ (with only $25 \%$ of stenosis in the BTK region, according to common definition), mean lesion length was $>100 \mathrm{~mm}$ reaching up to $130 \mathrm{~mm}$. Nearly all lesions showed de novo character, with higher total occlusion rates, than in the studies localized in the SFA region. In the IN.PACT DEEP $\mathrm{RCT},{ }^{26}>75 \%$ of the lesions were calcified and $>11 \%$ severely calcified.

At 12 months, the clinical parameter ABI improved significantly $(\sqrt{ })$ compared to the preinterventional values in the DEBATE BTK (also RU) and IN.PACT DEEP RCT. The improvement of both parameters was significantly higher in the DCB group in the DEBATE BTK study (Table 3). ${ }^{27}$ Amputation rates at 12 months were lower in the DCB group in the DEBELLUM, DEBATE-BTK, and BIOLUX-PII studies. $^{28}$

The actual investigation of DCBs in the BTK region was carried out by the IN.PACT-DEEP RCT. The study design was 2:1 and included 357 patients ( $69 \%-76 \%$ diabetics) with peripheral arterial disease with $\mathrm{RU} \geq 4$ (CLI stage): 239 patients were treated with IN.PACT Amphirion ${ }^{\mathrm{TM}}$ DCB and compared to 119 patients receiving standard PTA. While clinical characteristics were similar between the drug-eluting balloon (DEB) and PTA groups, other lesion-specific parameters such as mean lesion length, impaired inflow, and previous target limb revascularization displayed significant baseline differences. After 12 months, primary, nonsignificant efficacy results of DEB vs PTA were TLR of $9.2 \%$ vs $13.1 \%$ and LLL of $0.61 \mathrm{~mm}$ vs $0.62 \mathrm{~mm}$. While primary safety was met, a safety parameter driven by major amputation rate was observed: at 12 months, there was a trend toward an increased major amputation rate in the DEB arm compared to the PTA arm (8.8\% vs 3.6\%) (Table 3$){ }^{26}$

Figure 4 summarizes the TLR in the BTK studies at 12 months. While the DEBELLUM and DEBATE BTK studies reported significantly reduced TLR for the DCB cohort compared to the control, there were no significant differences in TLR in the IN.PACT DEEP and the BIOLUX PII studies. In the latter, PP and improvement of clinical outcome (RU) were superior after DCB treatment, but not significantly.

In summary, the IN.PACT Amphirion DCB was used in three trials in BTK lesions with controversial results:

Table 3 Clinical trials of DCB vs PTA in BTK lesions

\begin{tabular}{|c|c|c|c|c|c|c|c|c|}
\hline \multirow{3}{*}{$\begin{array}{l}\text { BTK RCT } \\
\text { DCB type used }\end{array}$} & \multirow{2}{*}{\multicolumn{2}{|c|}{$\begin{array}{l}\text { DEBELLUM }{ }^{* 25} \\
\text { IN.PACT }^{\mathrm{TM}} \text { Amphirion }\end{array}$}} & \multirow{2}{*}{\multicolumn{2}{|c|}{$\begin{array}{l}\text { DEBATE-BTK }^{27} \\
\text { IN.PACT }^{\mathrm{TM}} \text { Amphirion }\end{array}$}} & \multirow{2}{*}{\multicolumn{2}{|c|}{$\begin{array}{l}\text { IN.PACT DEEP }{ }^{26} \\
\text { IN.PACT TM }^{\mathrm{T}} \text { Amphirion }\end{array}$}} & \multirow{2}{*}{\multicolumn{2}{|c|}{$\begin{array}{l}\text { BIOLUX-PII }{ }^{28} \\
\text { Passeo-I8 LuX }\end{array}$}} \\
\hline & & & & & & & & \\
\hline & DCB & PTA & DCB & PTA & DCB & PTA & DCB & PTA \\
\hline \multicolumn{9}{|l|}{ Characteristics } \\
\hline Number of patients (n) & 25 & 25 & 65 & 67 & 239 & 119 & 36 & 36 \\
\hline Diabetics (\%) & 52 & 36 & 100 & 100 & 76 & 69 & 61 & 72 \\
\hline CLI (\%) & 36 & 40 & 100 & 100 & 100 & 99 & 78 & 78 \\
\hline Lesion length $(\mathrm{mm})^{\mathrm{a}}$ & $75 \pm 35$ & $74 \pm 35$ & $129 \pm 83$ & $|3| \pm 79$ & $101 \pm 91$ & $129 \pm 95$ & $113 \pm 88$ & $115 \pm 87$ \\
\hline De novo lesion (\%) & 100 & 100 & 100 & 100 & 93 & 96 & & \\
\hline Total occlusion (\%) & 21 & 22 & 77 & 82 & 39 & 46 & & \\
\hline Calcified lesion (\%) & & & & & 75 & 78 & 36 & II \\
\hline Severe calcification (\%) & & & & & 14 & 11 & & \\
\hline \multicolumn{9}{|l|}{12 months } \\
\hline Improvement RU & & & Yes & $\sqrt{ }$ & & & & \\
\hline Improvement $\mathrm{ABI}$ & & & Yes & $\sqrt{ }$ & $\sqrt{ }$ & $\sqrt{ }$ & & \\
\hline Amputation rate (\%) & 4.0 & 12.0 & 0 & 1.5 & 8.8 & 3.6 & 3.3 & 5.7 \\
\hline
\end{tabular}

Notes: $\sqrt{ }$ Indicates significant improvement. ${ }^{\mathrm{D} D a t a}$ presented as mean \pm standard deviation. IN.PACT TM Amphirion DCB (Medtronic GmbH, Meerbusch, Germany); Passeo- 18 Lux DCB (Biotronik SE and Co, KG, Berlin, Germany); DEBELLUM, Lower Limb Multilevel Treatment with Drug-Eluting Balloon Trial; DEBELLUM*I, 75\% ATK and 25\% BTK; DEBATE-BTK, Drug-Eluting Balloon in Peripheral Intervention for Below the Knee Angioplasty Evaluation Trial; IN.PACT DEEP, Study of IN.PACT Amphirion ${ }^{\text {TM }}$ Drug Eluting Balloon vs Standard PTA for the Treatment of Below the Knee Critical Limb Ischemia; BIOLUX-PII, BIOTRONIK's First-in-Men Study of the Passeo-I8 LUX Drug Releasing PTA Balloon Catheter vs the Uncoated Passeo 18 Balloon Catheter in Subjects Requiring Revascularization of Infrapopliteal Arteries. Adapted with permission from Herten M, Schönefeld E, Stahlhoff S, Schwindt A, Torsello GB. Drug-coated balloons in the treatment of femoro- and infra-popliteal lesions. Interv Cardiol. 20I5;7(4):353-370. ${ }^{72}$ Abbreviations: ABI, ankle-brachial index; ATK, above the knee; BTK, below the knee; CLI, critical limb ischemia; DCB, drug-coated balloon; LLL, late lumen loss; PTA, percutaneous transluminal angioplasty; RCT, randomized controlled trial; RU, Rutherford classification. 


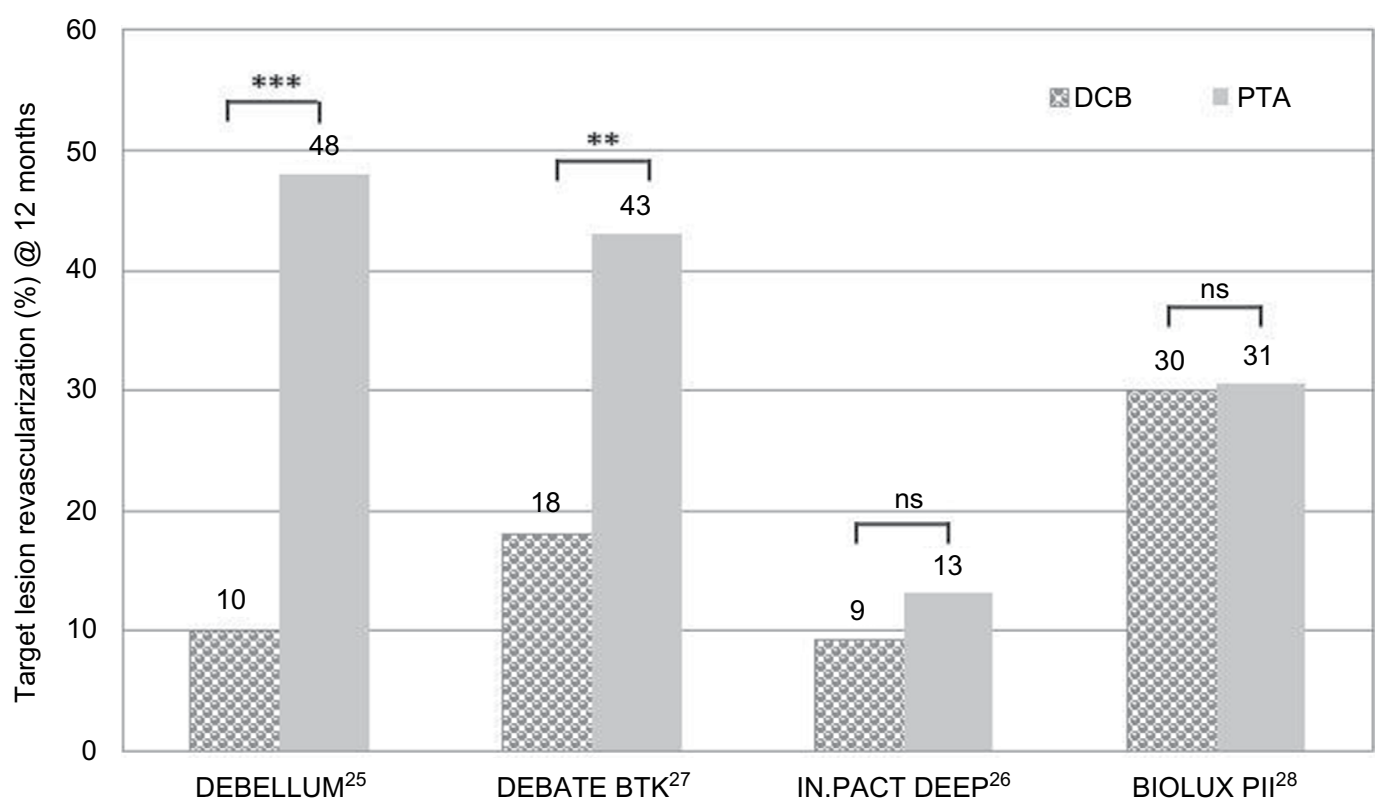

Figure 4 Comparison of TLR at 12 months in clinical trials of DCB vs PTA in BTK lesions.

Notes: **P $\leq 0.01$; ***P $\leq 0.001$. DEBELLUM, Lower Limb Multilevel Treatment with Drug-Eluting Balloon Trial; DEBELLUM*I, 75\% ATK and 25\% BTK; DEBATE-BTK, DrugEluting Balloon in Peripheral Intervention for Below the Knee Angioplasty Evaluation Trial; IN.PACT DEEP, Study of IN.PACT Amphirion ${ }^{\text {TM }}$ Drug Eluting Balloon vs Standard PTA for the Treatment of Below the Knee Critical Limb Ischemia; BIOLUX-PII, BIOTRONIK's First-in-Men Study of the Passeo-I8 LUX Drug Releasing PTA Balloon Catheter vs the Uncoated Passeo 18 Balloon Catheter in Subjects Requiring Revascularization of Infrapopliteal Arteries.

Abbreviations: BTK, below the knee; DCB, drug-coated balloon; ns, not significant; PTA, percutaneous transluminal angioplasty; TLR, target lesion revascularization.

although in the smaller-sized trials, DEBELLUM (25 vs 25 patients) and the DEBATE-BTK (65 vs 67 patients), the DCB showed superior performance, in the most recent IN.PACT DEEP trial, 358 patients were enrolled in a DCB: PTA 2:1 design. After 12 months, the outcome of the DCB group was not significantly different, but there was a trend towards a better limb salvage in the PTA arm. As a consequence, the IN.PACT ${ }^{\mathrm{TM}}$ Amphirion DCB was withdrawn from the market.

In addition to the studies listed in Table 3, the IN.PACT BTK $^{29}$ registry prospectively collected 104 patients $(83 \%$ CLI) with a mean lesion length of $176 \mathrm{~mm}$. Using historical data of uncoated balloons as comparison, the early restenosis rate of long-segment infrapopliteal disease was significantly lower after treatment with DEBs. At 12 months, clinical improvement was present in $91 \%$ and TLR rate was $17 \% .^{29}$

In the Biolux PII trial, 72 patients ( $61 \%-72 \%$ diabetics, $78 \%$ CLI patients) were treated in a 1:1 design with the Passeo 18 DCB or with an uncoated balloon. At 12 months, patency loss and TLR were not statistically different between the groups. Limb salvage rates were high in both groups ( $>94 \%$ ). Additionally, there were no differences in mortality, major amputation, and thrombosis rates. ${ }^{28}$

An ongoing global trial on DCB in the BTK context is looking at limb salvage and PP at 12 months FU (Lutonix BTK clinical trial). Preliminary results from a single center with 208 patients treated with Lutonix DCB (69\% diabetic,
$82 \%$ CLI patients; mean lesion length: $242 \pm 122 \mathrm{~mm}$ ) were promising: they presented $89 \%$ and $77 \%$ freedom from TLR and $97 \%$ and $96 \%$ freedom from major amputations at 6 months and 12 months, respectively. ${ }^{30}$

Patients with stenosis or occlusions of the lower limb have mostly highly complex lesions with long lengths, calcifications, and the urgent need for recanalization because of critical ischemia. Life expectancy and limb salvage rates are poor. The concept of early DCB for the SFA region seems to be not transferable to the lower limb. While in the SFA region, the efficacy of the DCB seems to correlate with parameters such as lesion type and freedom from calcification, the design of studies for the BTK region, especially the treatment of CLI, must also address specific features. In addition to limb preservation, which includes wound care, wound healing, and blood flow (clinical parameters RU and ABI), the patients' functional status and health-related quality of life are important aspects. Early studies on DCB efficacy in the BTK region were limited by not including a standardized wound therapy in their protocol and not considering terms of wound healing as an end point.

\section{DCB use in ISR lesions of the SFA}

While most studies address de novo lesions, data on efficacy of DCB in restenotic lesions and for ISR are scarce. Table 4 summarizes studies and registries containing data about DCB use in ISR lesions (lesion length: 81-137 mm) 
Table 4 Clinical trials of DCB vs PTA in ISR of the SFA

\begin{tabular}{|c|c|c|c|c|c|c|c|}
\hline \multirow{3}{*}{$\begin{array}{l}\text { Femoropopliteal } \\
\text { RCT and registry } \\
\text { DCB type used }\end{array}$} & \multirow{3}{*}{$\begin{array}{l}\text { Italian registry }^{3 \mid} \\
\text { IN.PACT }{ }^{\mathrm{TM}} \\
\text { DCB } \\
\end{array}$} & \multicolumn{2}{|c|}{ DEBATE ISR ${ }^{35}$} & \multicolumn{2}{|l|}{ FAIR $^{34}$} & \multicolumn{2}{|c|}{ COPA CABANA $^{33}$} \\
\hline & & \multicolumn{2}{|c|}{ IN.PACT ${ }^{\mathrm{TM}}$ Admiral } & \multicolumn{2}{|c|}{ IN.PACT ${ }^{\mathrm{TM}}$ Admiral } & \multicolumn{2}{|c|}{ Cotavance ${ }^{\circledR}$} \\
\hline & & DCB & PTA & DCB & PTA & DCB & PTA \\
\hline \multicolumn{8}{|l|}{ Characteristics } \\
\hline Number of patients (n) & 39 & 44 & 42 & 62 & 57 & 47 & 41 \\
\hline Diabetics (\%) & 49 & 100 & 100 & 45 & 30 & 43 & 46 \\
\hline CLI (\%) & & 75 & 67 & 4,8 & 10,5 & 8 & 11 \\
\hline Lesion length $(\mathrm{mm})^{\mathrm{a}}$ & $83 \pm 39$ & $132 \pm 86$ & $137 \pm 82$ & $82 \pm 71$ & $81 \pm 66$ & $119 \pm 96$ & $109 \pm 78$ \\
\hline Lesion type (\%) & ISR & ISR & ISR & ISR & ISR & ISR & ISR \\
\hline Total occlusion (\%) & 20 & & & 24 & 33 & 18 & 35 \\
\hline Bailout stenting (\%) & 10,3 & 15,9 & 26,2 & 1,6 & 7,0 & & \\
\hline \multicolumn{8}{|l|}{12 months } \\
\hline Improvement RU & & & & Yes & $\sqrt{ }$ & & \\
\hline Improvement $\mathrm{ABI}$ & & & & $\sqrt{ }$ & $\sqrt{ }$ & & \\
\hline
\end{tabular}

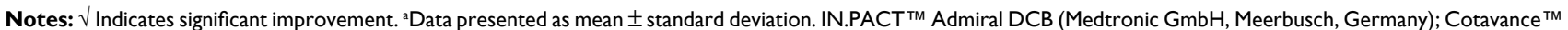
DCB (Medrad, Bayer Healthcare, Berlin, Germany); DEBATE ISR, Trial Drug Eluting Balloon in Peripheral Intervention for In-Stent Restenosis; FAIR, Drug Eluting Balloon vs PTA for Superficial Femoral Artery In-Stent Restenosis Trial; COPA CABANA trial, Cotavance ${ }^{\mathrm{TM}}$ Paclitaxel Coated Balloons vs Uncoated Balloon Angioplasty for Treatment of In-Stent Restenosis in SFA and the Popliteal Arteries. Adapted with permission from Herten M, Schönefeld E, Stahlhoff S, Schwindt A, Torsello GB. Drug-coated balloons in the treatment of femoro- and infra-popliteal lesions. Interv Cardiol. 2015;7(4):353-370.72

Abbreviations: ABI, ankle-brachial index; CLI, critical limb ischemia; DCB, drug-coated balloon; ISR, in-stent restenosis; LLL, late lumen loss; PTA, percutaneous transluminal angioplasty; RCT, randomized controlled trial; RU, Rutherford classification; SFA, superficial femoral artery.

in the SFA. ${ }^{31-35}$ The number of diabetic and CLI patients was higher than in the herein-cited studies (up to $100 \%$ diabetics in DEBATE ISR ${ }^{35}$ and $67 \%-75 \%$ CLI in the FAIR ${ }^{34}$ and the COPA CABANA trials. ${ }^{33}$ At 12 months, all studies showed promising TLR rates after DCB treatment compared to the respective uncoated control (Figure 5). In the FAIR trial, the clinical data (RU and $\mathrm{ABI}$ ) also improved significantly $(\sqrt{ })$ after 12 months compared to the preinterventional value (Table 4) ${ }^{36}$ While data from COPA CABANA and FAIR trials report data at 12 months FU, so far, midterm results are only available from the DEBATE ISR study. Here, no significant differences in TLR rate could be observed between the groups at 24 months $^{35}$ and 36 months. ${ }^{37}$ Especially, the treatment of more complex ISR lesions (Tosaka class III $^{38}$ ) was associated with an increased rate of TLR, irrespective of the technology used (DEB or PTA). ${ }^{37}$

There are currently several investigations on DCB performance in SFA-ISR: the PLAISIR study (ClinicalTrials.gov identifier: NCT01587482) and the ISAR-PEBIS RCT (ClinicalTrials.gov identifier: NCT01083394). In the PACUBA I RCT, the efficacy of the Freeway 035 DCB (Eurocor, Bonn, Germany) in SFA-ISR lesions compared to standard PTA will be investigated (ClinicalTrials.gov identifier: NCT01247402).

\section{De novo vs restenosis - different effectiveness - different pathology?}

In previous studies, most of the lesions treated with DCB showed a de novo character. First indications for a different efficacy of the DCB in de novo vs restenosis can be found in the PACIFIER trial. A subgroup analysis of 44 lesions treated with DCB identified better results in terms of LLL in the de novo vs restenosis group. A retrospective comparison of efficacy of DCBs in restenotic ( $\mathrm{n}=46$; including ISR) vs de novo lesions $(n=65)$ revealed that DCB treatment for femoropopliteal lesions showed significantly better performance in de novo stenosis or occlusions than in restenosis (PP: $93 \%$ vs $81 \%$ at 6 months and $85 \%$ vs $68 \%$ at 12 months, respectively). ${ }^{39}$

The different effect of DCB on de novo vs restenotic lesions could be due to discrepancies in the PTX distribution at the target cells. Several animal studies demonstrated that PTX reaches the SMC layer despite intimal plaque in de novo stenotic vessels. ${ }^{6,40}$ In restenotic lesions, a vascular injury was seen following vessel dilation and/or after stenting, which stimulates the mitotic cell cycle for subsequent repair mechanisms. SMCs change their contractile phenotype to a dedifferentiated synthetic phenotype, in which the SMCs start to secrete extracellular matrix components. ${ }^{41}$ Restenosis occurs when this proinflammatory regenerative process is not counterbalanced by appropriate stimuli for matrix-degrading enzymes (matrix metalloproteinases). The composition of the extracellular matrix components changes from a provisional fibrin-rich one to a permanent matrix. These changes are accompanied by reduced SMC density. ${ }^{41}$ The innermost vessel layer forming the restenosis consists mainly of noncellular material. The cytotoxic effect of the PTX may not be able to reach the cellular layer of 


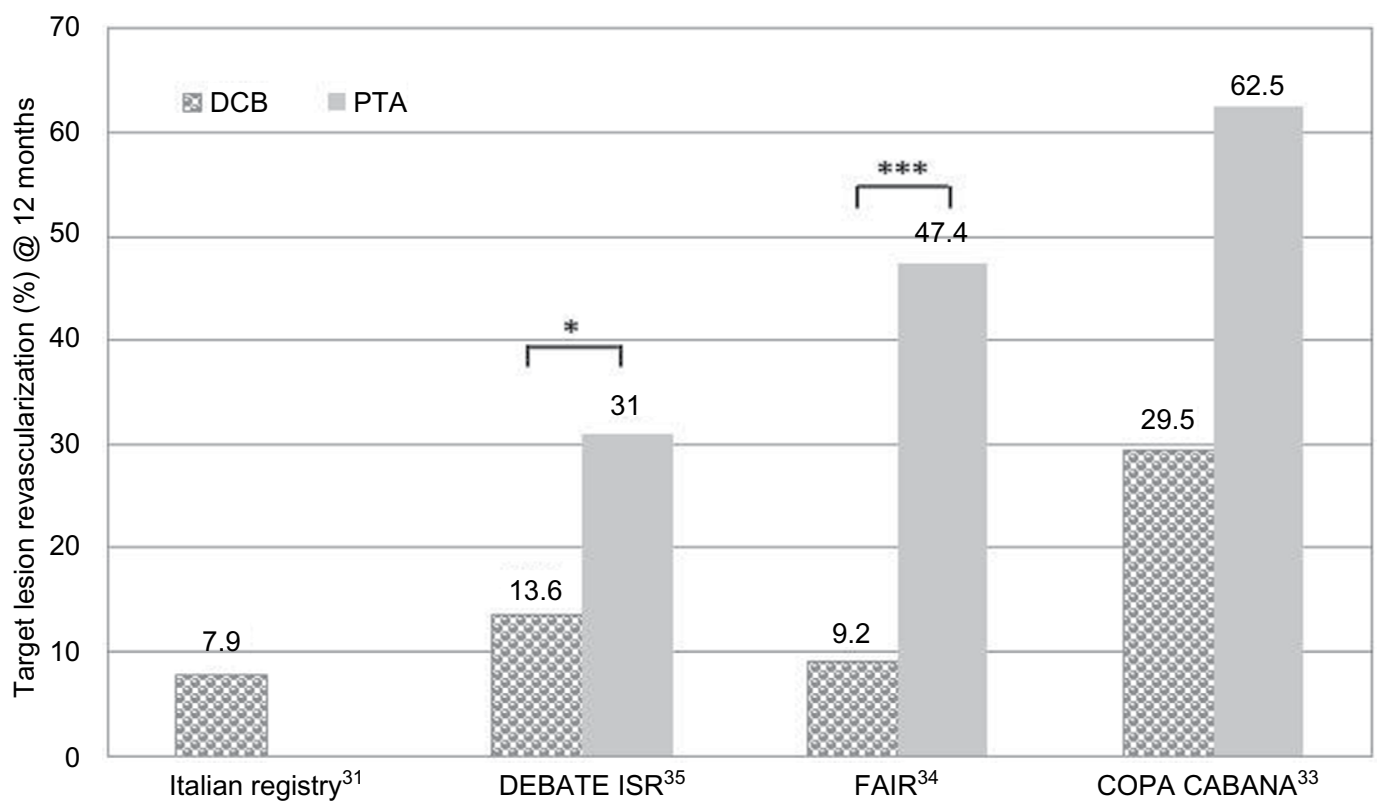

Figure 5 Comparison of TLR at 12 months in clinical trials with DCB vs PTA in ISR of the SFA.

Notes: $* P \leq 0.05 ; * * * P 0.00 I$. DEBATE ISR, Trial Drug Eluting Balloon in Peripheral Intervention for In-Stent Restenosis; FAIR, Drug Eluting Balloon vs PTA for Superficial Femoral Artery In-Stent Restenosis Trial; COPA CABANA trial, Cotavance ${ }^{\mathrm{TM}}$ Paclitaxel Coated Balloons vs Uncoated Balloon Angioplasty for Treatment of In-Stent Restenosis in SFA and the Popliteal Arteries.

Abbreviations: DCB, drug-coated balloon; ISR, in-stent restenosis; PTA, percutaneous transluminal angioplasty; SFA, superficial femoral artery; TLR, target lesion revascularization.

the SMCs. ${ }^{42}$ Removal of these inner layers might enable the PTX to reach the target cells.

\section{Difficulty in calcification - predictor of poor results?}

In a recent study by Fanelli et al, 60 patients with calcified lesions of the SFA were treated with DCB therapy. Thereby, the calcium burden and its impact on DCB effectiveness were investigated. ${ }^{43}$ Data revealed that calcium had a proportional impact on restenosis formation because the DCB effect was lower in patients with a higher degree of calcium, indicating that calcium seems to be a predictor of decreased efficacy of DCB. On closer scrutiny, it appeared that the length of the calcified stenosis was less relevant, but its localization within the vessel was of major importance: a greater impact could be observed in circumferential vs longitudinal distribution. ${ }^{43}$

In a recent investigation, the efficacy of DEB therapy in 91 patients with femoropopliteal arterial disease was associated with patient, lesion, and procedure variables, including calcification. After 6 months, the median LLL was $0.2 \mathrm{~mm}$ overall. Severity of lesion calcification was associated with LLL after treatment with DEB and varied significantly across lesions with differing severities of calcification. However, LLL did not differ based on calcium location (intimal, medial, or mixed) or calcium length. Additional predictors of LLL after DEB treatment included diabetes, coronary artery disease, and prior intervention. Interestingly, the severity of residual stenosis after intervention did not have any impact on LLL during FU. ${ }^{44}$

A possible approach to overcome this limitation of DEB efficacy might be plaque modification or removal prior to DEB usage.

\section{Intravascular plaque removal - debulking atherectomy}

While PTA modifies the obstruction in the lesions by a disruptive stretching process, atherectomy (AR) has the potential to remove the lesion material. Different principles are used for percutaneous excision. Mechanical plaque removal devices consist of a rotational cutting device, which deals with the excised atherosclerotic tissue in different ways and, optional, continuous perfusion of saline: while it is captured in the tip in directional AR (DA) devices (SilverHawk ${ }^{\mathrm{TM}}$, TurboHawk ${ }^{\mathrm{TM}}$; Covidien, Dublin, Ireland), now HawkOne ${ }^{\mathrm{TM}}$ (Medtronic, Minneapolis, MN, USA), ${ }^{45,46}$ it is concurrently aspirated in rotational AR devices (Jetstream; Bayer Pathway PV system, Pathway Medical Technologies, Kirkland, WA, USA; Phoenix AR catheter, AtheroMed, Menlo Park, CA, USA). ${ }^{45,46}$ Orbital AR uses a rotational device with an eccentric, abrasive crown producing minuscule particulates not requiring embolic protection (CSI Diamondback Orbital atherectomy 
system; Cardiovascular Systems, Inc, St Paul, MN, USA). ${ }^{47}$ Apart from these three, excimer laser AR (LA) removes atherosclerotic plaques by photoablation (atheroablation) with a laser (Turbo-Booster/Turbo-Elite laser catheter; Spectranetics, Colorado Springs, CO, USA).

In order to minimize the risk of peripheral embolization, embolic protection filters are recommended and considered a reasonable strategy to avoid distal thromboembolism.

Currently, there are four FDA-approved AR devices available with good procedural results. Most of the published evidence supporting their use consists of single-arm observational studies or case series. None of the so-far published studies evaluated any remarkable safety issue; however, it has to be stated that for the ultimate application in ISR, the application of DA and rotational AR are still off label use and not approved for ISR treatment. ${ }^{48}$

The DEFINITIVE LE trial demonstrates that DA in infrainguinal arteries resulted in promising technical and clinical results at 12 months for claudicants (intermittent claudication [IC]) and CLI patients. The 1-year PP rate was 84\% (IC: $90 \%$ and CLI patients: $78 \%$ ), and the freedom from major amputation rate was $97 \%$ (IC: $100 \%$ and CLI: 94\%). In both IC and CLI patients, significant improvements in RU and objective measures of walking distance and quality of life were seen at 1 year in comparison to baseline. $^{49}$

In a systematic review, six RCTs comprising 287 patients undergoing debulking AR vs balloon angioplasty PTA, for the treatment of femoropopliteal artery occlusive disease were analyzed. While the technical success was similar between the AR and the PTA groups ( $94 \%$ vs $96 \%$ ), after a median FU of 9 months, both groups showed similar patency. The authors concluded that in their analysis of a limited body of studies with high risk of bias, debulking AR of the SFA did not seem to confer any procedural advantage or improvement in clinical outcome relative to PTA alone. ${ }^{50}$

However, despite favorable acute periprocedural results, mechanical AR seems to be limited by low patency rate, and the long-term benefit in relation to restenosis and clinical outcomes is still controversial.

Additional RCTs are necessary to prove the efficacy and cost-effectiveness of these AR techniques, as well as to define their role in contemporary endovascular practice. Similar to PTA, debulking is traumatic to the vessel wall and triggers an inflammatory response, especially in case of damage of the elastic lamina. Up to now, it has not yet been proven that AR is sufficient as a stand-alone therapy - a combination with DCBs might be promising.

\section{Outcome of DCB therapy with prior debulking}

Lesion preparation through an uncoated balloon before DCB angioplasty seems to be essential for calcified and complex lesions. The rationale behind combining AR and DCBs is that removal of plaque facilitates local delivery of the antiproliferative drug and might therefore optimize drug delivery to the vessel wall.

First studies comparing the effect of DA and DCBs vs DA followed by an uncoated control in femoropopliteal ISR lesions demonstrated superior results in terms of TLR for the combination DA + DCBs at 12 months (Table 5). ${ }^{51}$ The removal of atherosclerotic plaque prior to DCB use yielded significantly lower TLR rate than the sole use of DCB in ISR lesions of the SFA after 12 months (Figure 6). ${ }^{52}$

In the DEFINITIVE AR RCT, 102 patients with moderate calcified lesions were treated either with DA + DCB $(n=48)$ and compared to 54 patients with DCB treatment only. There was higher technical success and lower incidence of flowlimiting dissection in the DA + DCB group. At 12 months, the $\mathrm{DA}+\mathrm{DCB}$ group was superior to the $\mathrm{DCB}$-alone group in terms of LLL ( 4.4 vs $3.8 \mathrm{~mm}, P<0.05$ ) and PP restenosis rates, but the latter was without statistical significance. A third subgroup included 19 patients with severely calcified lesions treated with DA + DCB. The data suggested trends favoring DA + DCB in lesions $\geq 10 \mathrm{~cm}$ and in severely calcified lesions. ${ }^{53}$

Other trials such as the ADCAT (NCT01763476) are currently investigating the performance of AR followed by DCB angioplasty over DCB angioplasty alone, which will be compared in long de novo, infrapopliteal lesions.

\section{Cost-effectiveness}

Several reports addressed the cost-effectiveness of DCBs for the treatment of infrainguinal peripheral artery disease.

Calculations by Diehm and Schneider on the costeffectiveness of PTX-DCB for femoropopliteal arterial obstructions used a simplified decision-analytic model based on TLR rates at 12 months reported in literature. Using the Swiss diagnosis-related groups (DRG) system, baseline and FU costs associated with in-hospital patient treatment were calculated, which revealed that the use of DEBs may be cost-effective through prevention of TLR at 1 year of FU. ${ }^{54}$

Budget analysis by Pietzsch et al looked into four main endovascular strategies - DCB, DES, bare metal stent (BMS), and PTA - for the treatment of peripheral arterial disease published in RCTs until December 2012. The 24-month 
Table 5 Clinical trials combining debulking and DCB in the SFA

\begin{tabular}{|c|c|c|c|c|c|c|}
\hline \multirow{3}{*}{$\begin{array}{l}\text { Debulking + } \\
\text { DCB RCT } \\
\text { Study design, } \\
\text { systems used }\end{array}$} & \multicolumn{2}{|c|}{ Sixt et al $(2013)^{51}$} & \multicolumn{2}{|c|}{ Gandini et al $(2013)^{52}$} & \multicolumn{2}{|c|}{$\begin{array}{l}\text { Tepe }(20 \text { I5) } \\
\text { (DEFINITIVE AR) }\end{array}$} \\
\hline & \multicolumn{2}{|c|}{$\begin{array}{l}\text { DA + DCB vs DA + PTA, } \\
\text { SilverHawk }^{T M}\end{array}$} & \multicolumn{2}{|c|}{$\begin{array}{l}\text { LA + DCB vs DCB only, } \\
\text { TurboElite Laser, Freeway } \\
\text { DCB } \AA\end{array}$} & \multicolumn{2}{|c|}{$\begin{array}{l}\text { DA + DCB vs DCB only, } \\
\text { SilverHawk } \\
\text { Hawk }^{\mathrm{TM}} \text {, Cotarbo } \\
\text { Cotance }^{\mathrm{TM}} \text { DCB }\end{array}$} \\
\hline & $\mathrm{DA}+\mathrm{DCB}$ & DA + PTA & LA+DCB & DCB & $\mathrm{DA}+\mathrm{DCB}$ & DCB \\
\hline \multicolumn{7}{|l|}{ Characteristics } \\
\hline Number of patients (n) & 29 & 60 & 24 & 24 & 48 & 54 \\
\hline CLI & 42 & 17 & 100 & 100 & & \\
\hline Lesion length $(\mathrm{mm})^{\mathrm{a}}$ & $153 \pm 93$ & $180 \pm 136$ & $200 \pm 101$ & $233 \pm 91$ & 113 & 97 \\
\hline Lesion type & $93 \%$ ISR & $60 \%$ ISR & $100 \%$ ISR & $100 \%$ ISR & & \\
\hline \multicolumn{7}{|l|}{ Total occlusion (\%) } \\
\hline Severe calcification (\%) & & & 25 & 42 & 25 & 19 \\
\hline \multicolumn{7}{|l|}{12 months } \\
\hline Distal embolization, $\mathrm{n}$ & 5 & 7 & 1 & 2 & 3 & 0 \\
\hline Limb salvage (\%) & & & 92 & 54 & 100 & 100 \\
\hline Ulcer healing (\%) & & & 87 & 62 & & \\
\hline Amputation rate, $\mathrm{n}$ & & & 8,3 & 45,8 & 0 & 0 \\
\hline
\end{tabular}

Notes: ${ }^{\mathrm{D} D}$ ata presented as mean \pm standard deviation. Cotavance ${ }^{\mathrm{TM}} \mathrm{DCB}$ (Medrad, Bayer Healthcare, Berlin, Germany); Freeway DCBß (Eurocor GmbH, Bonn, Germany); SilverHawk ${ }^{\mathrm{TM}}$, TurboHawk ${ }^{\mathrm{TM}}$ Plaque Excision Systems (Covidien-EV3, Dublin, Ireland); TurboElite Laser (Spectranetics, Corporation, Leusden, the Netherlands); DEFINITIVEAR, Study of the SilverHawk/TurboHawk Plaque Excision Systems Used With SpiderFX to Treat Calcified Peripheral Arterial Disease. Adapted with permission from Herten M, Schönefeld E, Stahlhoff S, Schwindt A, Torsello GB. Drug-coated balloons in the treatment of femoro- and infra-popliteal lesions. Interv Cardiol. 20I5;7(4):353-370.72

Abbreviations: CLI, critical limb ischemia; DA, directional atherectomy; DCB, drug-coated balloon; LA, laser atherectomy; ISR, in-stent-restenose; PTA, percutaneous transluminal angioplasty; RCT, randomized controlled trial; RU, Rutherford classification; SFA, superficial femoral artery.

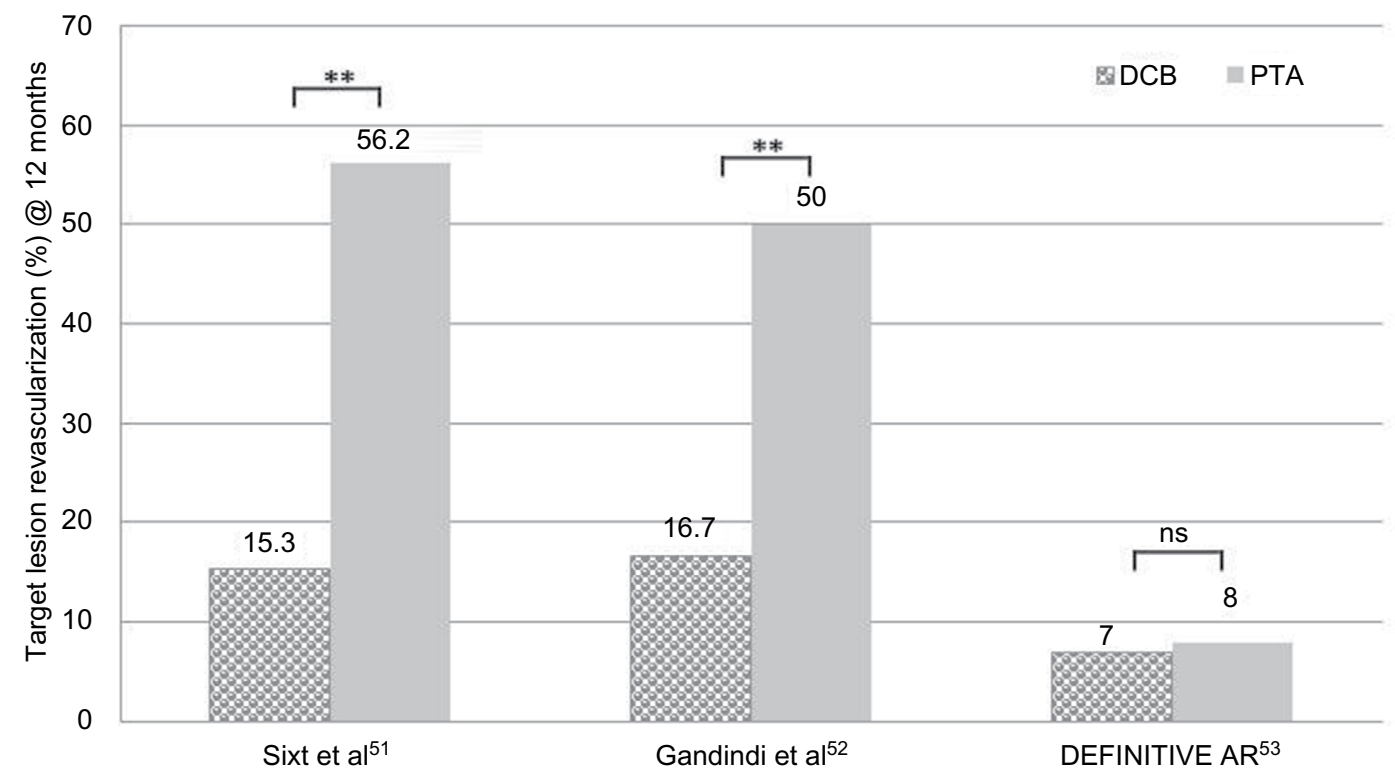

Figure 6 Comparison of TLR at 12 months in clinical trials combining debulking and DCB in the SFA.

Notes: ${ }^{*} P \leq 0.01$. DEFINITIVE-AR, Study of the SilverHawk/TurboHawk Plaque Excision Systems Used With SpiderFX to Treat Calcified Peripheral Arterial Disease. Abbreviations: DCB, drug-coated balloon; ns, not significant; SFA, superficial femoral artery; TLR, target lesion revascularization.

probability of TLR for each treatment was weighted by sample size. A decision-analytic Markov model was applied to assess the budget impact from payers' and facility-providers' perspectives of the four index procedure strategies. The pooled 24-month probabilities were $14.3 \%, 19.3 \%, 28.1 \%$, and $40.3 \%$ for DCBs, DESs, BMSs, and PTAs, respectively.
The drug-eluting strategies had a lower projected budget impact over 24 months compared to BMSs and PTAs in the US Medicare and in the German public health care systems (US Medicare: US $\$ 10,214$ for DCBs, US $\$ 12,904$ for DESs, US $\$ 13,114$ for uncoated balloons, and US $\$ 13,802$ for BMSs; German public health care systems: $€ 3,619$ for DCBs, $€ 3,632$ 
for DESs, $€ 4,026$ for BMSs, and $€ 4,290$ for PTAs). The number needed to treat was 3.9 for DCB vs PTA, which means that for approximately every fourth lesion treated with DCB opposed to PTA, one TLR could be avoided over the period of 24 months. ${ }^{55}$

In an updated analysis of endovascular interventions, the scope of the scanned RCTs was extended until 2013. They received pooled 24-month probabilities of TLR of $16.5 \%$, $19.4 \%, 26.9 \%$, and $39.6 \%$ for DCBs, DESs, BMSs, and PTAs, respectively. The latest clinical evidence suggests that DCBs provide the most favorable clinical outcomes among the considered endovascular treatments for femoropopliteal artery disease. Their analysis depicted DESs and DCBs to be associated with the lowest cost to payers in the German health care system, with respective budget impacts of $€ 3,799$ for DESs, $€ 3,913$ for DCBs, $€ 4,189$ for BMSs, and $€ 4,451$ for PTAs. ${ }^{56}$

\section{Are DCBs the best treatment method? For SFA? For BTK? For ISR?}

A direct comparison of DCBs vs DESs in long femoropopliteal lesions presented comparable restenosis and TL rates, which were also similar to those in shorter lesions. The analysis of the subgroup DCB + BMS (bailout stenting) vs DES showed a trend toward better clinical outcome in terms of TLR.$^{57}$ The meta-analysis of DES vs PTA + BMS (611 vs 307 patients) in infrapopliteal arteries resulted in reduced risk for intervention, restenosis, and amputations for the DES therapy, while there were no differences in terms of survival and RU. ${ }^{58}$ In the Zilver PTX single arm study, DESs displayed good results in long de novo lesions, with PP rates of $77.6 \%$ and $74.8 \%$ and TLR rates of $14.6 \%$ and $19.5 \%$ after 12 months $^{59}$ and 24 months, ${ }^{60}$ respectively.

Recently, a meta-analysis investigated the efficacy of several endovascular techniques in the femoropopliteal artery in 16 RCTs comprising 2,532 patients with 4,227 person-years. They compared bare nitinol stents (BNSs), covered nitinol stents (CNSs), PTX- or sirolimus-eluting stents (PESs or SESs), and PTX-coated balloons (PCBs) with plain BA or with each other. BA served as the reference treatment, with a calculated median TLR rate of 22 events per 100 patient-years (py). In comparison to BA, all other options showed decreased rates of events, but the actual effect was variable. PCBs and PESs were the most efficacious (eight events/100 py (patient years) and nine events/100 py, respectively), whereas the remaining treatments showed a more modest effect: BNSs (16 events/100 py), CNSs (16 events/100 py), and SESs (14 events/100 py). PCB was associated with the highest probability $(56 \%)$ of being the best treatment (lowest rate of events), followed by PES, with $33 \%$ probability (PCB > PES $>$ SES $>$ CNS $>$ BNS $>$ BA) ${ }^{61}$

At the moment, there still seems to be a lack of Level I evidence of DCB efficacy in the BTK region. However, the early DCB concept for SFA may not be transferred as it is into the challenging BTK region - more complex solutions such as proper vessel bed preparation by debulking with AR or laser device, followed by treatment with a DCB, might be an alternative treatment concept. Currently, preliminary results of a global trial with a new-generation DCB in BKT reveal promising results. ${ }^{62}$ Concerning other techniques, the direct comparison of DCB vs drug-coated stents has shown significantly reduced restenosis rates in the DCB group at 6 months. ${ }^{62}$

In ISR, recent studies showed superior results for DCBs, with TLR rates for DCB of $9.2 \%$ and $30 \%$ which were significantly lower than those for appropriate standard PTA, with $47 \%$ and $63 \%$, respectively. ${ }^{33,34}$ Potential alternative endovascular treatment options for ISR, apart from balloon angioplasty (PTA), are brachytherapy, cutting or scoring balloon technique, cryoplasty, and repeated stenting with a nitinol stent, stentgraft, or DES. ${ }^{63}$ Their initial success rates are high and the complication rates low even in complex lesions. However, recurrent restenosis limits the long-term durability of most of these therapies. ${ }^{63}$ In a retrospective study, the treatment of femoropopliteal ISR with endovascular brachytherapy showed PP of $80 \%$ at 12 months. ${ }^{64}$ A small study comparing peripheral cutting balloon angioplasty with PTA in ISR (22 vs 17 patients) revealed high recurrence rates of $65 \%$ vs $73 \%$ at 6 months. ${ }^{65}$ The evaluation of cryoplasty brought up poor results in three smaller studies, with $\sim 100 \%$ recurrence at 12 months. ${ }^{66-68}$ The treatment of femoropopliteal ISR with a heparin-bonded VIABAHN ${ }^{\circledR}$ endoprosthesis (W L Gore and Associates GmbH, Putzbrunn, Germany) showed significantly better results than treatment with a standard balloon at 1 year, with PP rates of $75 \%$ vs $25 \% .{ }^{69}$ The placement of a second stent layer using a DES (Zilver® PTX; Cook Medical, Bloomington, IN, USA) revealed PP rates of $79 \%$ at 12 months. ${ }^{69,70}$ However, long-term durability of most of these therapies has not been proven yet. ${ }^{63}$

\section{Summary}

Ultimately, there are many trials and superior results for DCB therapy vs PTA alone in femoropopliteal lesions. The currently available DCB systems are different and efficacies are different - up to now, all of them are safe. There are no 
reported significant differences in distal embolization or amputation rates.

Studies mostly vary among the defined end points or inclusion-and-exclusion criteria. Currently, there are no trials comparing one DCB against another. Additionally, there is still lack of respectable prospective long-term data to state the long-term superiority of one DCB technology.

A novel cathether-guided drug delivery system (Bullfrog ${ }^{\circledR}$ Micro-Infusion Device; Mercator MedSystems, San Leandro, CA, USA) is currently being tested in two clinical trials (DANCE in the US [NCT01507558], LIMBO [LIMBO PTA: NCT02479555; LIMBO ATX: NCT02479620] in Germany) to infuse therapeutic agents directly and nonsystemically through the blood vessel wall into deep tissues. After femoropopliteal revascularization via AR and/or PTA, the anti-inflammatory drug plus a mixture of dexamethasone and contrast agent is administered to the adventitia of the treated lesion to enhance clinical efficacy and to intervene with the vessel response at an earlier stage. Preliminary results at 12 months of the DANCE trial reported high patency rates of $85 \%$ in 73 patients after AR of the SFA or femoropopliteal stenosis. The level of proinflammatory cytokines (monocyte chemoattractive protein 1, $\mathrm{MCP}-1$ ) and acute-phase reactants (C-reactive protein [CRP]) were reduced significantly 1 day and 30 days after the infusion. ${ }^{71}$

In conclusion, DCB stand-alone therapy gives excellent results in TASC IIA and IIB femoropopliteal lesions. However, the DCB concept does not overcome the early failure modes of PTA such as recoil and dissection. Because calcium seems to be a predictor of decreased efficacy of DCB, modern recanalization tools and techniques make endovascular therapy feasible for TASC IIC and IID lesions. Highly complex SFA and BTK lesions need lesion- and patient-tailored approaches that take into account the RU classification, lesion location, lesion length, grade of calcification, and patients' comorbidities and renal function. Aspects such as limb preservation (including wound care, wound healing, and blood flow), the patients' functional status, and health-related quality of life need to be considered. These individually tailored approaches will for certain include plaque modulation and debulking techniques such as laser or mechanical AR, DCBs, and nitinol stents as part of the treatment concept.

\section{Disclosure}

The authors report no conflicts of interest in this work.

\section{References}

1. Conrad MF, Kang J, Cambria RP, et al. Infrapopliteal balloon angioplasty for the treatment of chronic occlusive disease. J Vasc Surg. 2009;50(4):799-805.
2. Mwipatayi BP, Hockings A, Hofmann M, Garbowski M, Sieunarine $\mathrm{K}$. Balloon angioplasty compared with stenting for treatment of femoropopliteal occlusive disease: a meta-analysis. J Vasc Surg. 2008; 47(2):461-469.

3. Chaabane C, Otsuka F, Virmani R, Bochaton-Piallat ML. Biological responses in stented arteries. Cardiovasc Res. 2013;99(2):353-363.

4. Creel CJ, Lovich MA, Edelman ER. Arterial paclitaxel distribution and deposition. Circ Res. 2000;86(8):879-884.

5. Levin AD, Vukmirovic N, Hwang CW, Edelman ER. Specific binding to intracellular proteins determines arterial transport properties for rapamycin and paclitaxel. Proc Natl Acad Sci USA. 2004;101(25):9463-9467.

6. Axel DI, Kunert W, Goggelmann C, et al. Paclitaxel inhibits arterial smooth muscle cell proliferation and migration in vitro and in vivo using local drug delivery. Circulation. 1997;96(2):636-645.

7. Kelsch B, Scheller B, Biedermann M, et al. Dose response to paclitaxelcoated balloon catheters in the porcine coronary overstretch and stent implantation model. Invest Radiol. 2011;46(4):255-263.

8. Cremers B, Speck U, Kaufels N, et al. Drug-eluting balloon: very shortterm exposure and overlapping. Thromb Haemost. 2009;101(1):201-206.

9. Margolis J, McDonald J, Heuser R, et al. Systemic nanoparticle paclitaxel (nab-paclitaxel) for in-stent restenosis I (SNAPIST-I): a first-in-human safety and dose-finding study. Clin Cardiol. 2007;30(4):165-170.

10. Gray W. Are all DCB equal? LINC Leipzig, Germany; 2015. Available from: http://linc2015.cloudcontrolled.com/media/15t_1_1420_Gray.pdf. Accessed February 19, 2015.

11. Cremers B, Biedermann M, Mahnkopf D, Bohm M, Scheller B. Comparison of two different paclitaxel-coated balloon catheters in the porcine coronary restenosis model. Clin Res Cardiol. 2009;98(5):325-330.

12. Bondesson P, Lagerqvist B, James SK, Olivecrona GK, Venetsanos D, Harnek J. Comparison of two drug-eluting balloons: a report from the SCAAR registry. EuroIntervention. 2012;8(4):444-449.

13. Tepe G. DCBs: look to the data. LINC Today - the official newspaper of LINC. 2015 (Issue 1):4.

14. Tepe G, Zeller T, Albrecht T, et al. Local delivery of paclitaxel to inhibit restenosis during angioplasty of the leg. N Engl J Med. 2008; 358(7):689-699.

15. Werk M, Langner S, Reinkensmeier B, et al. Inhibition of restenosis in femoropopliteal arteries: paclitaxel-coated versus uncoated balloon: femoral paclitaxel randomized pilot trial. Circulation. 2008; 118(13):1358-1365.

16. Werk M, Albrecht T, Meyer DR, et al. Paclitaxel-coated balloons reduce restenosis after femoro-popliteal angioplasty: evidence from the randomized PACIFIER trial. Circ Cardiovasc Interv. 2012;5(6):831-840.

17. Scheinert D, Duda S, Zeller T, et al. The LEVANT I (Lutonix paclitaxelcoated balloon for the prevention of femoropopliteal restenosis) trial for femoropopliteal revascularization: first-in-human randomized trial of low-dose drug-coated balloon versus uncoated balloon angioplasty. JACC Cardiovasc Interv. 2014;7(1):10-19.

18. Cassese S, Byrne RA, Ott I, et al. Paclitaxel-coated versus uncoated balloon angioplasty reduces target lesion revascularization in patients with femoropopliteal arterial disease: a meta-analysis of randomized trials. Circ Cardiovasc Interv. 2012;5(4):582-589.

19. Rosenfield K, Jaff MR, White CJ, et al; LEVANT 2 Investigators. Trial of a paclitaxel-coated balloon for femoropopliteal artery disease. $N E n g l$ J Med. 2015;373(2):145-153.

20. Tepe G, Laird J, Schneider P, et al. IN.PACT SFA Trial Investigators. Drug-coated balloon versus standard percutaneous transluminal angioplasty for the treatment of superficial femoral and/or popliteal peripheral artery disease: 12-month results from the IN.PACT SFA Randomized Trial. Circulation. 2015;131(5):495-502.

21. Duda S. ILLUMENATE FIH: direct DCB cohort - first results. LINC Leipzig, Germany; 2015. Available from: http://linc2015.cloudcontrolled.com/media/15th_1_0830_Duda.pdf. Accessed February 19, 2015.

22. Schroeder H, Meyer DR, Lux B, Ruecker F, Martorana M, Duda S. Two-year results of a low-dose drug-coated balloon for revascularization of the femoropopliteal artery: outcomes from the ILLUMENATE first-in-human study. Catheter Cardiovasc Interv. 2015;86(2):278-286. 
23. Tepe G, Schnorr B, Albrecht T, et al. Angioplasty of femoral-popliteal arteries with drug-coated balloons: 5-year follow-up of the THUNDER Trial. JACC Cardiovasc Interv. 2015;8(1 Pt A):102-108.

24. Tepe G, Zeller T, Schnorr B, et al. High-grade, non-flow-limiting dissections do not negatively impact long-term outcome after paclitaxel-coated balloon angioplasty: an additional analysis from the THUNDER study. J Endovasc Ther. 2013;20(6):792-800.

25. Fanelli F, Cannavale A, Boatta E, et al. Lower limb multilevel treatment with drug-eluting balloons: 6-month results from the DEBELLUM randomized trial. $J$ Endovasc Ther. 2012;19(5):571-580.

26. Zeller T, Baumgartner I, Scheinert D, et al. IN.PACT DEEP Trial Investigators. Drug-eluting balloon versus standard balloon angioplasty for infrapopliteal arterial revascularization in critical limb ischemia: 12-month results from the IN.PACT DEEP randomized trial. $J$ Am Coll Cardiol. 2014;64(15):1568-1576.

27. Liistro F, Porto I, Angioli P, et al. Drug-eluting balloon in peripheral intervention for below the knee angioplasty evaluation (DEBATE-BTK): a randomized trial in diabetic patients with critical limb ischemia. Circulation. 2013;128(6):615-621.

28. Zeller T, Beschorner U, Pilger E, et al. Paclitaxel-coated balloon in infrapopliteal arteries: 12-month results from the BIOLUX P-II randomized trial (BIOTRONIK'S-first in man study of the Passeo-18 LUX drug releasing PTA balloon catheter vs. the uncoated Passeo-18 PTA balloon catheter in subjects requiring revascularization of infrapopliteal arteries). JACC Cardiovasc Interv. 2015;8(12):1614-1622.

29. Schmidt A, Piorkowski M, Werner M, et al. First experience with drugeluting balloons in infrapopliteal arteries: restenosis rate and clinical outcome. J Am Coll Cardiol. 2011;58(11):1105-1109.

30. Steiner S. German single center experience with Lutonix DCB in BTK. LINC Leipzig, Germany; 2015. Available from: http://linc2015. cloudcontrolled.com/media/15w_1_1454_S.\%20Steiner.pdf. Accessed February 19, 2015.

31. Stabile E, Virga V, Salemme L, et al. Drug-eluting balloon for treatment of superficial femoral artery in-stent restenosis. $\mathrm{J} \mathrm{Am} \mathrm{Coll} \mathrm{Cardiol.}$ 2012;60(18):1739-1742.

32. Liistro F, Grotti S, Porto I, et al. Drug-eluting balloon in peripheral intervention for the superficial femoral artery: the DEBATE-SFA randomized trial (drug eluting balloon in peripheral intervention for the superficial femoral artery). JACC Cardiovasc Interv. 2013;6(12):1295-1302.

33. Tepe G. The Copa Cabana study: DEB vs. POBA in in-stent restenosis. LINC, Leipzig, Germany; 2015. Available from: http://linc2015.cloudcontrolled.com/media/15t_1_1620_Tepe.pdf. Accessed February 19, 2015.

34. Krankenberg H, Tubler T, Ingwersen M, et al. Drug-coated balloon versus standard balloon for superficial femoral artery in-stent restenosis: the randomized femoral artery in-stent restenosis (FAIR) Trial. Circulation. 2015;132(23):2230-2236.

35. Liistro F, Angioli P, Porto I, et al. Paclitaxel-eluting balloon vs. standard angioplasty to reduce recurrent restenosis in diabetic patients with in-stent restenosis of the superficial femoral and proximal popliteal arteries: the DEBATE-ISR study. $J$ Endovasc Ther. 2014;21(1):1-8.

36. Krankenberg H. DCB and ISR: inside from the FAIR study. LINC Leipzig, Germany; 2015. Available from: http://linc2015.cloudcontrolled.com/media/15t_1_1410_Krankenberg.pdf. Accessed February 19,2015

37. Grotti S, Liistro F, Angioli P, et al. Paclitaxel-eluting balloon vs standard angioplasty to reduce restenosis in diabetic patients with in-stent restenosis of the superficial femoral and proximal popliteal arteries: three-year results of the DEBATE-ISR study. $J$ Endovasc Ther. 2016;23(1):52-57.

38. Tosaka A, Soga Y, Iida O, et al. Classification and clinical impact of restenosis after femoropopliteal stenting. $J$ Am Coll Cardiol. 2012; 59(1):16-23.

39. Herten M, Torsello GB, Schonefeld E, Imm B, Osada N, Stahlhoff S. Drug-eluting balloons for femoropopliteal lesions show better performance in de novo stenosis or occlusion than in restenosis. JVasc Surg. 2015;61(2):394-399.
40. Schnorr B, Kelsch B, Cremers B, Clever YP, Speck U, Scheller B. Paclitaxel-coated balloons - survey of preclinical data. Minerva Cardioangiol. 2010;58(5):567-582.

41. Yahagi K, Otsuka F, Sakakura K, et al. Pathophysiology of superficial femoral artery in-stent restenosis. $J$ Cardiovasc Surg (Torino). 2014;55(3):307-323.

42. Van den Berg JC. Towards a better understanding and more efficient treatment of in-stent restenosis. J Cardiovasc Surg (Torino). 2014; 55(3):305-306.

43. Fanelli F, Cannavale A, Gazzetti M, et al. Calcium burden assessment and impact on drug-eluting balloons in peripheral arterial disease. Cardiovasc Intervent Radiol. 2014;37(4):898-907.

44. Tepe G, Beschorner U, Ruether C, et al. Drug-eluting balloon therapy for femoropopliteal occlusive disease: predictors of outcome with a special emphasis on calcium. J Endovasc Ther. 2015;22(5):727-733.

45. Al Khoury G, Chaer R. Evolution of atherectomy devices. J Cardiovasc Surg (Torino). 2011;52(4):493-505.

46. Quevedo HC, Arain SA, Ali G, Abi Rafeh N. A critical view of the peripheral atherectomy data in the treatment of infrainguinal arterial disease. J Invasive Cardiol. 2014;26(1):22-29.

47. Adams GL, Khanna PK, Staniloae CS, Abraham JP, Sparrow EM. Optimal techniques with the Diamondback 360 degrees system achieve effective results for the treatment of peripheral arterial disease. $J$ Cardiovasc Transl Res. 2011;4(2):220-229.

48. Beschorner U, Zeller T. Combination of mechanical atherectomy and drug-eluting balloons for femoropopliteal in-stent restenosis. J Cardiovasc Surg (Torino). 2014;55(3):347-349.

49. Rastan A, McKinsey JF, Garcia LA, et al. One-year outcomes following directional atherectomy of infrapopliteal artery lesions: subgroup results of the prospective, multicenter DEFINITIVE LE Trial. J Endovasc Ther. 2015;22(6):839-846.

50. Diamantopoulos A, Katsanos K. Atherectomy of the femoropopliteal artery: a systematic review and meta-analysis of randomized controlled trials. J Cardiovasc Surg (Torino). 2014;55(5):655-665.

51. Sixt S, Carpio Cancino OG, Treszl A, et al. Drug-coated balloon angioplasty after directional atherectomy improves outcome in restenotic femoropopliteal arteries. J Vasc Surg. 2013;58(3):682-686.

52. Gandini R, Del Giudice C, Merolla S, Morosetti D, Pampana E, Simonetti G. Treatment of chronic SFA in-stent occlusion with combined laser atherectomy and drug-eluting balloon angioplasty in patients with critical limb ischemia: a single-center, prospective, randomized study. J Endovasc Ther. 2013;20(6):805-814.

53. Tepe G. DCB + atherectomy for complex lesions: DEFINITIVE AR - final data. LINC, Leipzig, Germany; 2015. Available from: http:// linc2015.cloudcontrolled.com/media/15t_1_1005_Tepe.pdf. Accessed February 19, 2015

54. Diehm N, Schneider H. Cost-effectiveness analysis of paclitaxel-coated balloons for endovascular therapy of femoropopliteal arterial obstructions. J Endovasc Ther. 2013;20(6):819-825.

55. Pietzsch JB, Geisler BP, Garner AM, Zeller T, Jaff MR. Economic analysis of endovascular interventions for femoropopliteal arterial disease: a systematic review and budget impact model for the United States and Germany. Catheter Cardiovasc Interv. 2014;84(4): 546-554.

56. Pietzsch JB, Geisler BP, Zeller T. Endovascular interventions for treatment of femoropopliteal peripheral artery disease: updated budget impact analysis for Germany based on latest clinical evidence. Value Health. 2015;18(7):A349.

57. Zeller T, Rastan A, Macharzina R, et al. Drug-coated balloons vs. drugeluting stents for treatment of long femoropopliteal lesions. J Endovasc Ther. 2014;21(3):359-368.

58. Fusaro M, Cassese S, Ndrepepa G, et al. Paclitaxel-coated balloon or primary bare nitinol stent for revascularization of femoropopliteal artery: a meta-analysis of randomized trials versus uncoated balloon and an adjusted indirect comparison. Int J Cardiol. 2013;168(4): $4002-4009$. 
59. Bosiers M, Peeters P, Tessarek J, Deloose K, Strickler S. Zilver PTX Single-Arm Study Investigators. The Zilver(R) PTX(R) Single Arm Study: 12-month results from the TASC C/D lesion subgroup. J Cardiovasc Surg (Torino). 2013;54(1):115-122.

60. Dake MD, Ansel GM, Jaff MR, et al. Sustained safety and effectiveness of paclitaxel-eluting stents for femoropopliteal lesions: 2-year follow-up from the Zilver PTX randomized and single-arm clinical studies. J Am Coll Cardiol. 2013;61(24):2417-2427.

61. Katsanos K, Spiliopoulos S, Karunanithy N, Krokidis M, Sabharwal T, Taylor P. Bayesian network meta-analysis of nitinol stents, covered stents, drug-eluting stents, and drug-coated balloons in the femoropopliteal artery. J Vasc Surg. 2014;59(4):1123-1133.

62. Siablis D, Kitrou PM, Spiliopoulos S, Katsanos K, Karnabatidis D. Paclitaxel-coated balloon angioplasty versus drug-eluting stenting for the treatment of infrapopliteal long-segment arterial occlusive disease: the IDEAS randomized controlled trial. JACC Cardiovasc Interv. 2014;7(9): 1048-1056.

63. Singh GD, Armstrong EJ, Laird JR. Femoropopliteal in-stent restenosis: current treatment strategies. J Cardiovasc Surg (Torino). 2014;55(3): 325-333.

64. Werner M, Scheinert D, Henn M, et al. Endovascular brachytherapy using liquid Beta-emitting rhenium-188 for the treatment of longsegment femoropopliteal in-stent stenosis. J Endovasc Ther. 2012;19(4): $467-475$.
65. Dick P, Sabeti S, Mlekusch W, et al. Conventional balloon angioplasty versus peripheral cutting balloon angioplasty for treatment of femoropopliteal artery in-stent restenosis: initial experience. Radiology. 2008;248(1):297-302.

66. Karthik S, Tuite DJ, Nicholson AA, et al. Cryoplasty for arterial restenosis. Eur J Vasc Endovasc Surg. 2007;33(1):40-43.

67. Wildgruber MG, Berger HJ. Cryoplasty for the prevention of arterial restenosis. Cardiovasc Intervent Radiol. 2008;31(6):1050-1058.

68. Shin SH, Baril DT, Chaer RA, Makaroun MS, Marone LK. Cryoplasty offers no advantage over standard balloon angioplasty for the treatment of in-stent stenosis. Vascular. 2013;21(6):349-354.

69. Bosiers M, Deloose K, Callaert J, et al. Superiority of stent-grafts for in-stent restenosis in the superficial femoral artery: twelve-month results from a multicenter randomized trial. J Endovasc Ther. 2015;22(1):1-10.

70. Zeller T, Dake MD, Tepe G, et al. Treatment of femoropopliteal in-stent restenosis with paclitaxel-eluting stents. JACC Cardiovasc Interv. 2013;6(3):274-281.

71. Owens CD [webpage on the Internet]. LINC Leipzig, Germany; 2016. Available from: https://linc2016.app.exo.io/media/1040_Christopher_Owens_26_01_2016_Room_1_Main_Arena_1.pdf. Accessed March 31, 2016.

72. Herten M, Schönefeld E, Stahlhoff S, Schwindt A, Torsello GB. Drugcoated balloons in the treatment of femoro- and infra-popliteal lesions. Interv Cardiol. 2015;7(4):353-370.
Vascular Health and Risk Management

\section{Publish your work in this journal}

Vascular Health and Risk Management is an international, peerreviewed journal of therapeutics and risk management, focusing on concise rapid reporting of clinical studies on the processes involved in the maintenance of vascular health; the monitoring, prevention and treatment of vascular disease and its sequelae; and the involvement of

\section{Dovepress}

metabolic disorders, particularly diabetes. This journal is indexed on PubMed Central and MedLine. The manuscript management system is completely online and includes a very quick and fair peer-review system, which is all easy to use. Visit http://www.dovepress.com/ testimonials.php to read real quotes from published authors. 